\title{
Copyright
}

by

Sung Hyun Kim

2010 
The Thesis Committee for Sung Hyun Kim

Certifies that this is the approved version of the following thesis:

\section{A Predictive Model for Sand Production in Poorly Consolidated Sands}

\section{APPROVED BY SUPERVISING COMMITTEE:}

Supervisor:

Mukul M. Sharma

Maša Prodanović 


\title{
A Predictive Model for Sand Production in Poorly Consolidated Sands
}

$$
\text { by }
$$

Sung Hyun Kim, B.S., M.S.

\author{
Thesis \\ Presented to the Faculty of the Graduate School of \\ The University of Texas at Austin \\ in Partial Fulfillment \\ of the Requirements \\ for the Degree of
}

Master of Science in Engineering

The University of Texas at Austin

December 2010 


\section{Dedication}

To my God and my family 


\section{Acknowledgements}

I would like to express my sincere gratitude to Dr. Mukul Sharma for his endless guidance during our weekly meetings, office visits, and of course his generosity, encouragement, and the friendly-yet-aggressive basketball games during the memorable fall-gatherings. I also wish to extend my thanks to Karn for his insight and willingness to help me with the research throughout my studies. I'd like to thank all of my friends in petroleum engineering especially the Korean guys for their support and morning carpools. I'd also like to thank Harvey Fitzpatrick and Ron Dusterhoft at Halliburton for their kindness and openness to share their insights.

Coming this far in my studies would have been impossible without both parents' constant support in every aspect of my life. My wife and daughter are the source of joy in my life everyday and that made any difficult days seem not so difficult.

Finally, I am thankful for everything God has provided me and I hope the experience of conducting research and writing this thesis serves as a testament and a reminder of where my strength comes from.

December 2010 


\begin{abstract}

\section{A Predictive Model for Sand Production in Poorly Consolidated Sands}

\author{
Sung Hyun Kim, M.S.E. \\ The University of Texas at Austin, 2010
}

Supervisor: Mukul M. Sharma

This thesis presents a model for the process of sand production that allows us to predict the stability of wellbores and perforation tunnels as well as mass of sand produced.

Past analytical, numerical, and empirical models on material failure and erosion mechanisms were analyzed. The sand production model incorporates shear and tensile failure mechanisms. A criterion for sand erosion in failed sand was proposed based on a force balance calculation on the sand face. It is shown that failure, post failure sand mechanics and flow-dominated erosion mechanisms are important in the sand production process. The model has a small number of required input parameters that can be directly measured in the lab and does not require the use of empirical correlations for determining sand erosion. The model was implemented in a numerical simulator. 
Three different experiments using different materials were simulated and the results were compared to test the model. The model-generated results successfully matched the sand production profiles in experiments. When the post-failure behavior of materials was well-known, the match between the simulation and experiment was excellent. Sensitivity studies on the effect of mechanical stresses, flow rates, cohesion, and permeability show qualitative agreement with experimental observations. In addition, the effect of two-phase flow was presented to emphasize the importance of the waterweakening of the sand. These results show that catastrophic sand production can occur following water breakthrough. Finally the impact of increasing sand cohesion by the use of sand consolidation chemicals was shown to be an effective strategy for preventing sand production. 


\section{Table of Contents}

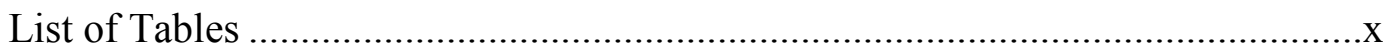

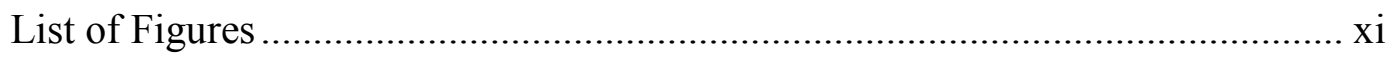

CHAPTER 1: INTRODUCTION

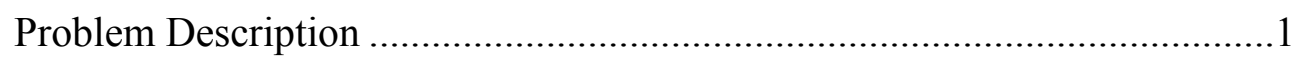

Motivation for the Sand Prediction Model .......................................................

Challenges in Understanding Sanding ..........................................................

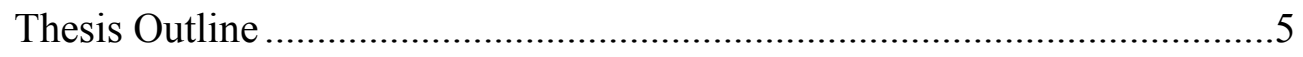

CHAPTER 2: LITERATURE REVIEW

Analytical Models for perforation stability ................................................

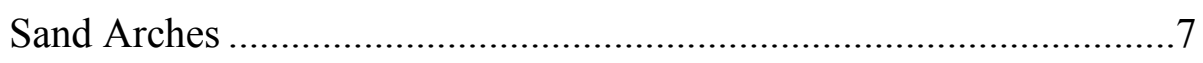

Stability of Wellbore / Perforation Wall ................................................11

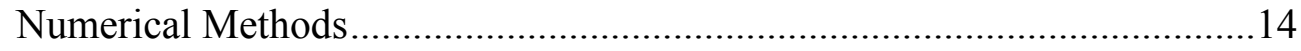

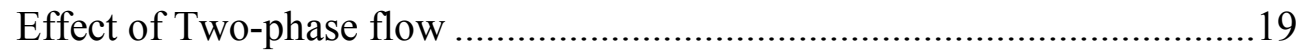

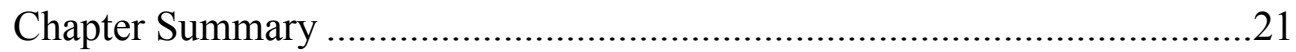

CHAPTER 3: MODEL Formulation AND NUMERICAL SimUlation 22

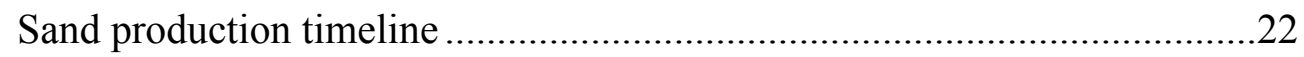

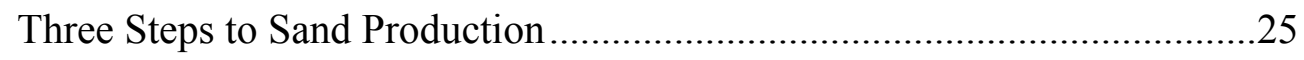

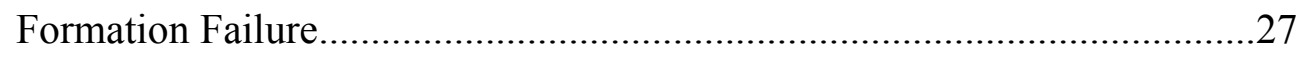

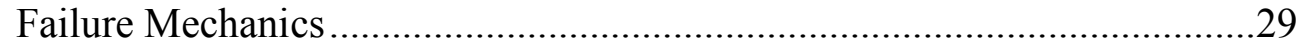

Formulation of Numerical Model ............................................................

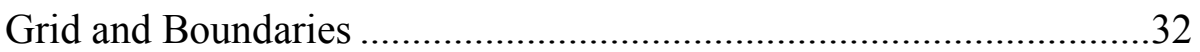

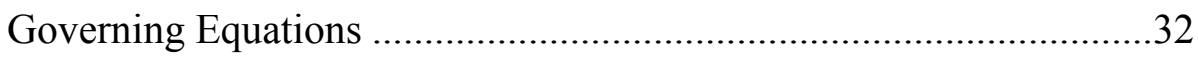

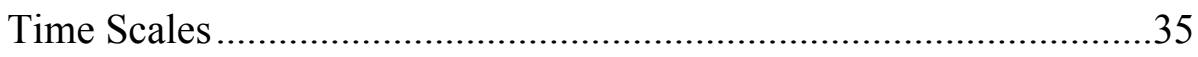

Sand Erosion: The Importance on Sand Production ......................................37

Erosion Criteria ........................................................................................

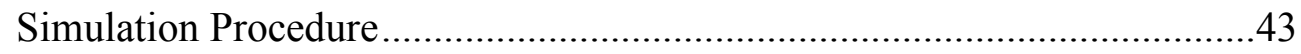

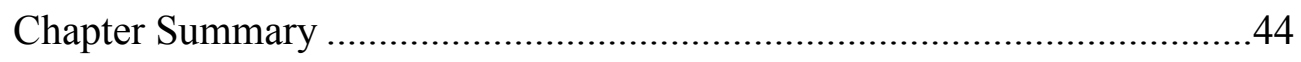

viii 


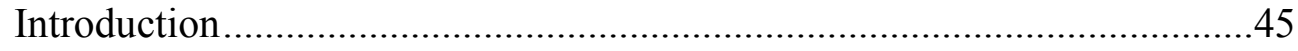

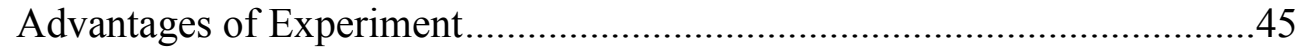

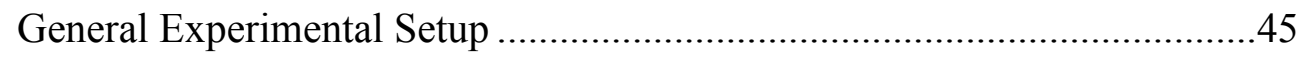

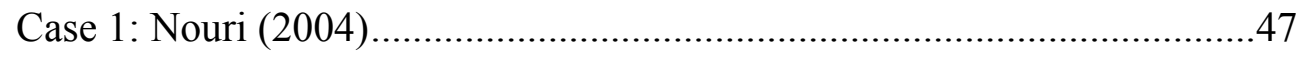

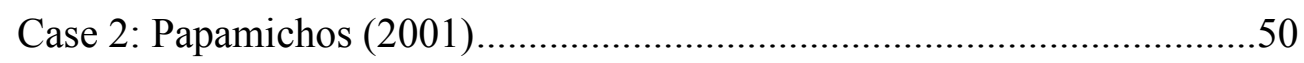

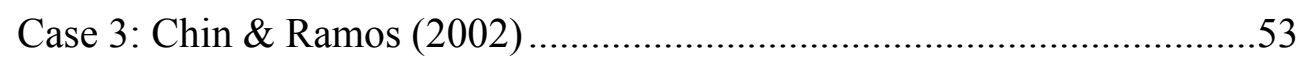

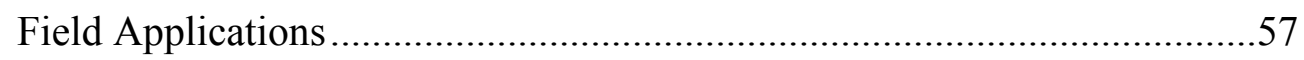

Transition from Experiments to Field - Some Considerations............57

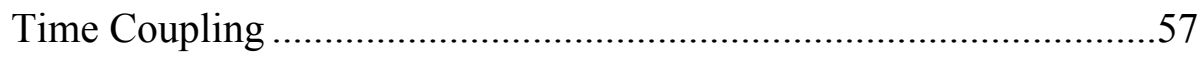

Specifying Model Parameters ......................................................58

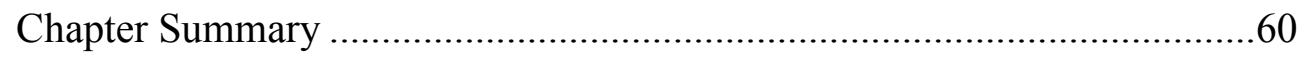

ChaPTER 5: Sensitivity STUdies

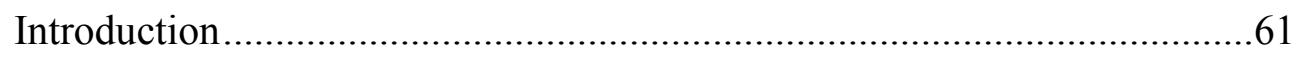

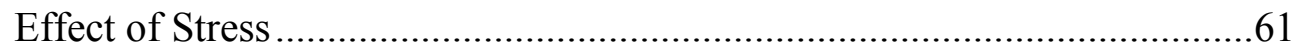

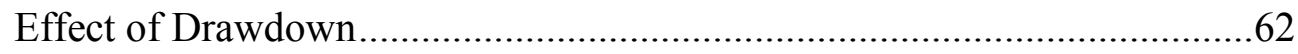

Consolidation / Cohesion .......................................................................64

Effect of Permeability Changes due to Failure ..........................................65

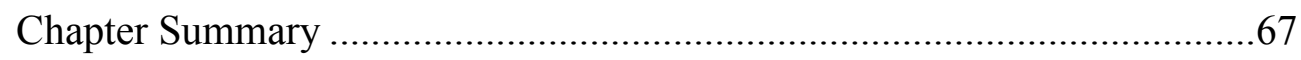

Chapter 6: SAnd Production in Multiphase Flow 68

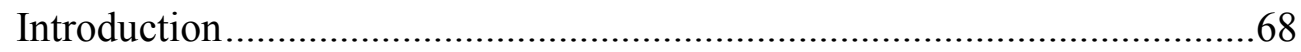

Sand Strength vs Water Saturation ..........................................................68

Effect of Two-phase Flow on Sand Production..........................................69

Simulation of Sand Production in Two-phase Flow ................................... 71

CHAPTER 7: CONCLUSIONS AND RECOMMENDATIONS

$\begin{array}{ll}\text { REFERENCES } & \mathbf{7 6}\end{array}$

$\begin{array}{ll}\text { VITA } & 81\end{array}$ 


\section{List of Tables}

Table 3.1: Sand production timeline .............................................................24

Table 4.1: Summary of material properties for experiments ............................47

Table 4.2: Material property changes during shear hardening (Nouri, 2004) .......48

Table 4.3: Use of sonic log to predict elastic moduli of materials ......................59

Table 4.4: Methods for obtaining material and petrophysical properties ..............59 


\section{List of Figures}

Fig 1.1: Model requirement ...........................................................................

Fig 1.2: Contribution from different knowledge sets into sand production model..5

Fig 2.1: Stress profiles in radial direction ......................................................... 10

(a) Prior to failure (b) After failure (Bratli and Risnes, 1981) ...............................10

Fig 2.2: Sanding with increasing water saturation (Bianco, 2001)........................19

Fig 3.1: Sanding rate change over time (Palmer, 2003) ........................................24

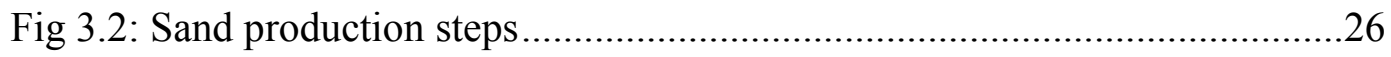

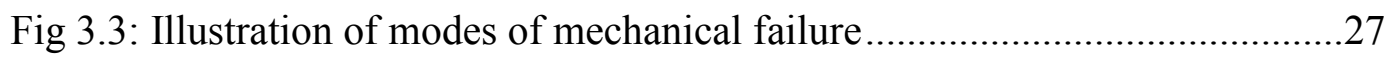

Fig 3.4: Dependence of failure on reservoir pressure and drawdown (Fjær, 2009)28

Fig 3.5: Failure envelope in relation to operating conditions (Fjær, 2009) ...........29

Fig 3.6: Bottom-hole pressure comparison in well A (Yi, 2004) a) Shear + Tensile model b) Shear only model .............................................................30

Fig 3.7: Bottom-hole pressure comparison in well B (Yi, 2004) a) Shear + Tensile model b) Shear only model ..............................................................

Fig 3.8: Calculation cycle (explicit) in FLAC3D (User Manual, FLAC3D 3.1)...35

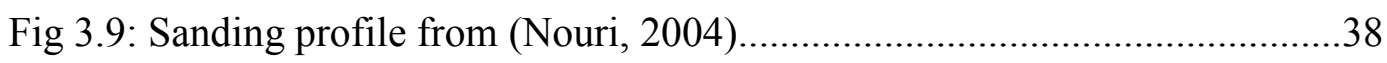

Fig 3.10: Stresses acting on a gridblock with one face open ...................................39

Fig 3.11: Simulation Flow Chart .......................................................................43

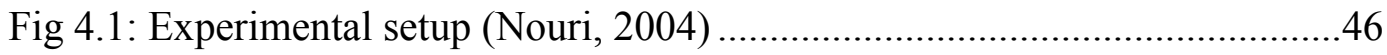

Fig 4.2: Sand production profile from experiment and simulation for varying axial

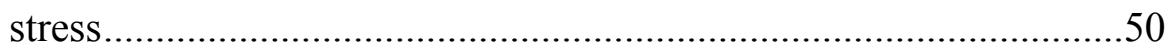

Fig 4.3: Sand production comparison at different confining stress (Papamichos, 2001) 
Fig 4.4: Sand production profile ................................................................52

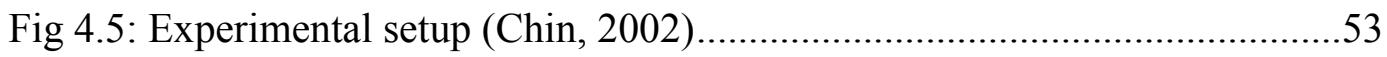

Fig 4.6: Failed material (in non-blue) and dimensions of failure after Test \#1 .....54

Fig 4.7: Sand production profile with cumulative flow and stress (Test \#1).........55

Fig 4.8: Sand production profile with cumulative flow and flow rate (Test \#2) ...56

Fig 4.9: Sand production profile with confining stress (Test \#3) .........................57

Fig 4.10: Reservoir simulation and sand prediction coupling a) Reservoir simulation with reservoir pressure change over time b) Sand prediction with varying stress and pore pressure levels ......................................58

Fig 5.1: Effect of external stress at a constant flow rate (Papamichos, 2001) ......62

Fig 5.2: Sand production profile with changes in stress and drawdown. .............63

Fig 5.3: Effect of flow rate at constant external stress (Papamichos, 2001).........64

Fig 5.4: Sand production profile for a consolidated sample ...............................65

Fig 5.5: Sand production profiles for permeability changes imposed on failed region

Fig 6.1: Effect of single-phase and two-phase flow on sand production (Papamichos,

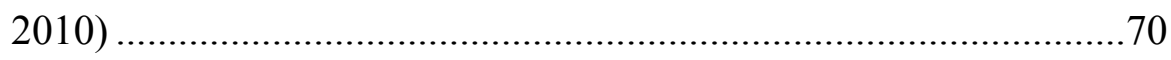

Fig 6.2: Effect of single-phase and two-phase flow on sand production...............71

Fig 6.3: Effect of water saturation on capillary cohesion $(\mathrm{Wu}, 2006) \ldots \ldots \ldots \ldots \ldots \ldots . . . .72$

Fig 6.4: Simulation of additional sand production caused by an increase in water

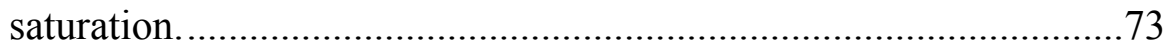

Fig 6.5: Sanding with increasing water saturation (Bianco, 2001) ......................73 


\section{CHAPTER 1: INTRODUCTION}

\section{Problem Description}

Sand production occurs in many fields across the world and it is especially common in wells in the Gulf of Mexico. Sedimentary rocks with an unconfined compressive strength of less than 1000 psi are considered poorly consolidated or weak and sanding potential is high in such formations. It has been shown that changes in in-situ stresses and hydrocarbon production can lead to sand failure in the near wellbore region.

During and after sand production, wells can sand-up and the productivity can decline. Disposal of produced sand is also a significant cost associated with producing such formations. Remedial procedures require hours of undesired rig time. Extreme cases with catastrophic failures have shown massive sanding and well abandonment. In highrate wells, sand can be transported to the surface and cause erosion of lines, joints, chokes, and valves. This poses serious safety risks to the workers. When sand production is identified, operators need monitoring devices and disposal systems in addition to remedial treatment or recompletions. In certain cases, such as heavy oil recovery, sand production is a deliberate production strategy and is utilized to enhance productivity (Cold Heavy Oil Production with Sand).

Many operators simply choose to install sand control or stimulate the formation if it is determined to be "weak" without necessarily evaluating or predicting the sand potential. Screens and gravel packs are widely used to prevent sand flowing into the wellbore and to the surface. Nevertheless, the initial costs are generally high and they are not free from problems. Screen systems come with a risk of failure by collapsing and 
bursting. Gravel packs can fail because of screen failure and plugging of the high permeability gravel. Frac and pack treatments bypass the damaged area of the wellbore and also stimulate the formation, yet sanding can still occur by the production of formation sand or proppant. In a different approach, sand consolidation treatments try to achieve small or no quantity of sand production from the formation, but the treatment often results in lower regained permeability and the longevity of the treatment is not guaranteed. In many cases, even with sand control completion in place, drawdown is carefully controlled throughout the life of the well to minimize the risk of sand production. However, this can bring about a disparity between the desired and feasible fluid production rate.

For an optimal sand control implementation, it is important to understand the outcome of each completion design. Hence, a need for the evaluation of sanding potential in a more qualitative and quantitative manner was identified. From the 1980s, industry has adopted the concept of sand management. In this approach it is essential to assess parameters such as production rate, drawdown, rock and fluid properties, and water cut that influence sand production and provide predictions for sand production rates. It is also important to assess how much sand production is acceptable or in some cases even desirable. The key to this thought is that if there is a negligible amount of sand predicted, then sand control may not be needed as long as the operation remains within the boundaries of the recommendations. However, sand prediction has been a difficult task for both the industry and academia for years. 
For one, reservoir conditions continuously change during the life of the well. Moreover, measurements of fluctuation and changes of the properties and conditions of the formation are scarce. Sanding information from field is rarely available. Identification of failure and its effects are well-known, yet mechanisms that contribute to the actual sand failure, erosion and transport are not clear.

\section{Motivation for the SAND Prediction Model}

Sand control methods must be considered and evaluated carefully for their benefits and disadvantages before any implementation. However, what should precede sand control design is the evaluation of whether the formation requires sand control or not and if it does, when and how much sanding occurs.

Many publications present sand failure and sand production models supported by experimental results. Some models deal with the problem of sand stability and failure (Bratli, 1981, Risnes, 1982) while others focus on the entrainment / transport of the sand after failure. However, most of these models rely on parameters that may or may not be experimentally measureable. In many instances the physical significance of some of these parameters is not obvious.

Consequently, the main objective of the research is to develop a general 3-D numerical model that describes the process of sand failure, erosion and production quantitatively. The model must be verifiable with distinct sets of experiments, which then could extend and offer a reasonable prediction tool for sand production characteristics for field cases. The numerical model should also be able to obtain results that are beyond the reach of simpler analytical solutions. 
A good model must incorporate

1. The essential physical phenomenon of sand production

2. Performance verified with experimental data

3. Have the ability to model and predict field performance.

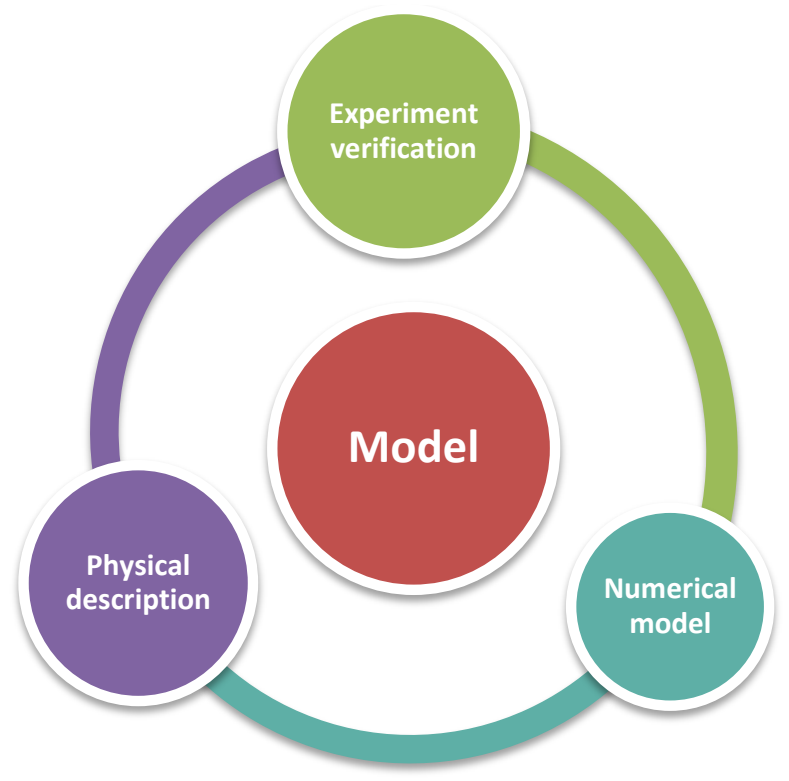

Fig 1.1: Model requirement

Computational efficiency is also important to the model because the goal of this work is to build a practical and usable model for users to obtain results in a reasonable time frame.

\section{Challenges in Understanding SANDing}

Many factors contribute to sanding such as: drawdown, depletion, water cut, and material properties. These aspects have been well explored individually. The challenge is to combine and relate these into one sand production model in a systematic manner. 


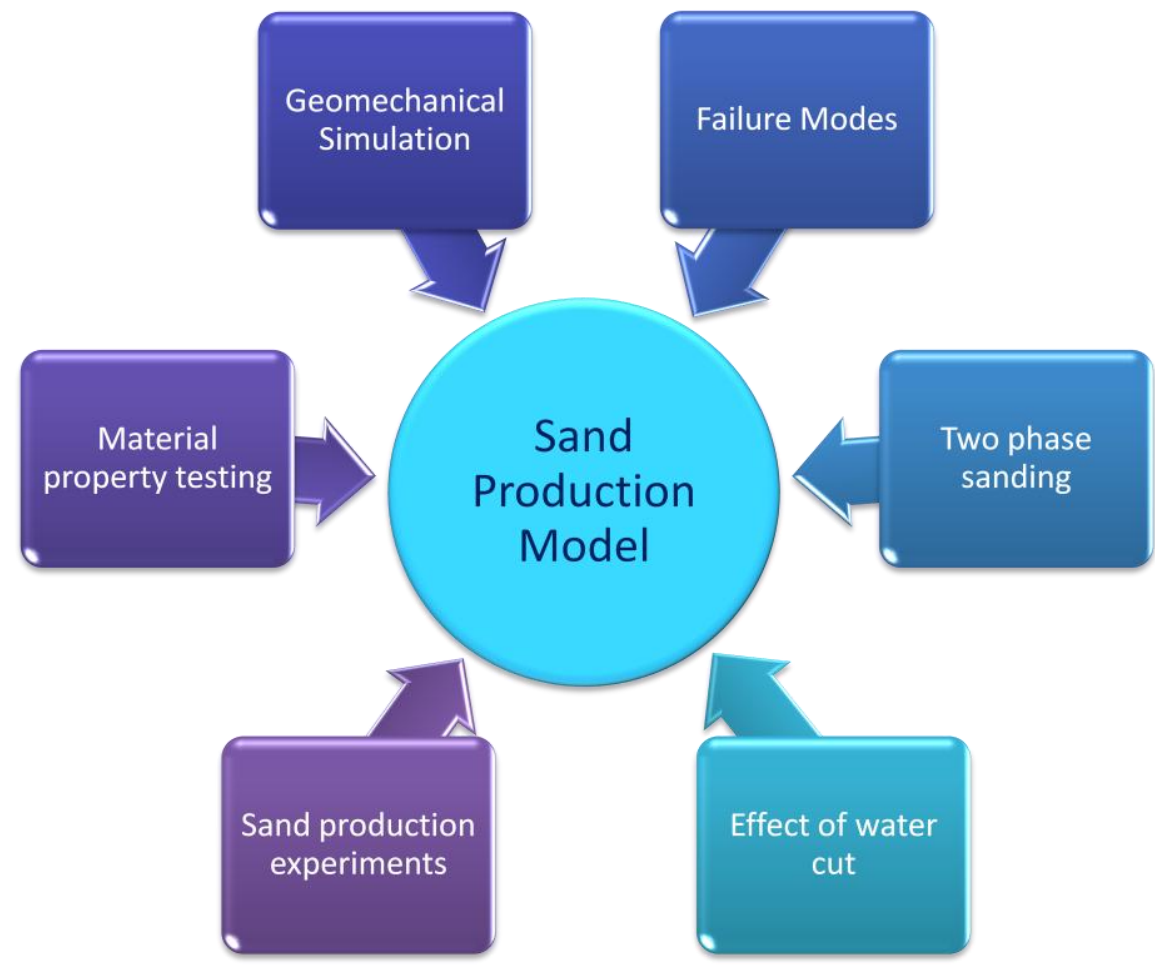

Fig 1.2: Contribution from different knowledge sets into sand production model

\section{Thesis OUTLINE}

This thesis consists of chapters that review the past work on sand prediction, mechanisms of sand production, and model verification. Chapter 2 reviews the literature from the emergence of the sand production issue to current developments. Experimental and analytical results from the literature provide a good basis to identifying the mechanisms of sand production. Chapter 3 focuses on formulating a model for sand production. Failure modes and relation to sanding potential are explained. An erosion model is presented in detail with supporting equations. Numerical simulation and its components are explained in the chapter. Finite Lagrangian Analysis in Continuum in 3D (FLAC3D) software is introduced and numerics along with FISH programming 
languagee are presented to the readers to understand the details of the sand prediction tool. Chapter 4 compares the model with experiments to verify that the model is robust and it is applicable to rocks and fluids of different properties and different boundary conditions. It also gives tips on modifying the numerical simulation for field applications and ways to obtain material and petrophysical properties relevant to sanding model. Chapter 5 is a compilation of sensitivity studies to understand the effect of flow rate (pressure), material properties, etc. Chapter 6 shows additional simulations with twophase flow which is not included in the original model. 


\section{CHAPTER 2: LITERATURE REVIEW}

Studies discussing the parameters affecting sand production have been published for decades. However, no clear consensus or model exists in the industry that will allow us to predict the onset of sanding and the amount of sand produced under a given set of conditions (Addis, 2008). In this chapter a brief review of the major conclusions of these past studies is presented.

\section{ANALYTICAL MODELS FOR PERFORATION STABILITY}

\section{Sand Arches}

Over 30 years ago, it was believed that sand production was governed by a phenomenon called sand arching. Theories suggested that formation material grains interlock through friction and cohesive force to create an arch shaped structure that provides enough resistance to withhold forces applied due to mechanical and hydrodynamic stresses.

Hall and Harrisberger (1970) presented data from arching experiments with unconsolidated sand, laying the ground work for conditions of sand arch formation, stabilization, and failure. Experiments studied various types of sand grains, wetting and non-wetting phase saturations, and applied loads. They determined that single-phase flow could not establish any strong arches even with angular grains due to the lack of forces holding the arch together. In two-phase flow, a sand arch formed and held unless the wetting phase flow disrupted the capillary cohesion which is essential to maintaining the arch strength. It was theorized that sand arches consisting of disaggregated / failed rock 
under formation stress formed a region that was in a plastic state, which with its unique arch shape was able to bear external loading.

Bratli and Risnes (1981), and Perkins and Weingarten (1988) formulated an analytical model for the stability of arches. To obtain analytical solutions to the stress cage problem, the geometry of the arch was assumed to be hemispherical. The condition of stress equilibrium in spherical coordinates was written as

$$
\frac{\partial \sigma_{r}}{\partial r}+\frac{1}{r}\left(2 \sigma_{r}-\sigma_{\theta}-\sigma_{\phi}\right)=0
$$

With symmetry in $\theta$ and $\phi$ directions,

$$
\frac{\partial \sigma_{r}}{\partial r}+\frac{2}{r}\left(\sigma_{r}-\sigma_{\theta}\right)=0
$$

Assuming no flow, the radius of the sand arch cavity $r_{c}$, cavity pore pressure $p_{c}$, and farfield stress $\sigma_{0}$, given by,

$$
\begin{gathered}
\sigma_{r}=\sigma_{0}-\left(\sigma_{0}-p_{c}\right)\left(\frac{r_{c}}{r}\right)^{3} \\
\sigma_{\theta}=\sigma_{0}+\frac{1}{2}\left(\sigma_{0}-p_{c}\right)\left(\frac{r_{c}}{r}\right)^{3}
\end{gathered}
$$

Flow was introduced to the equation with Darcy's law,

$$
q=4 \pi r^{2} \frac{k}{\mu} \frac{\partial p}{\partial r}
$$

Where $\mathrm{q}$ is the flow rate, $\mathrm{r}$ is distance from the center of the cavity, $\mathrm{k}$ is permeability, and $\mu$ is fluid viscosity. The stress profile with flow is determined to be, 


$$
\begin{aligned}
& \sigma_{r}=\sigma_{0}-\left[\sigma_{0}-p_{c}-2 \mu\left(p_{0}-p_{c}\right)\right]\left(\frac{r_{c}}{r}\right)^{3}-2 \mu\left(p_{0}-p_{c}\right) \frac{r_{c}}{r} \\
& \sigma_{\theta}=\sigma_{0}+\frac{1}{2}\left[\sigma_{0}-p_{c}-2 \mu\left(p_{0}-p_{c}\right)\right]\left(\frac{r_{c}}{r}\right)^{3}-\mu\left(p_{0}-p_{c}\right) \frac{r_{c}}{r}
\end{aligned}
$$

Where $\mathrm{p}_{0}$ is the far-field pore pressure. The Mohr-Coulomb criterion evaluates radial and tangential stresses to detect the onset of shear failure given by,

$$
\sigma_{\theta}=C_{0}+\sigma_{r} \tan ^{2} \beta
$$

Where $\varphi+\frac{\pi}{2}=2 \beta, \varphi$ is the friction angle, and $\mathrm{C}_{0}$ is the unconfined compressive strength (UCS). The region that undergoes failure near the cavity is defined to be plastified with a radius $R_{p}$, while the rest of the rock remains elastic. Both states were assumed to have constant material properties for simplicity. The radius of the plastic region near the cavity face was shown to be,

$$
\left(\frac{R_{p}}{r_{c}}\right)^{T}=\frac{3 \frac{T+1}{T+3}\left(\sigma_{0}-p_{c}\right)}{\frac{T+1}{T} 4 S_{\mathrm{o}} \tan \varphi-\frac{\mu q}{4 \pi k r_{c}}}
$$

Where $\mathrm{T}$ is a constant, $\mathrm{S}_{0}$ is the cohesion, and $\varphi$ is the friction angle. Fig 2.1 shows the initial stress profiles with a high contrast in effective normal stresses and post failure stress profile where the stresses in the region of failure have an altered stress profile. 

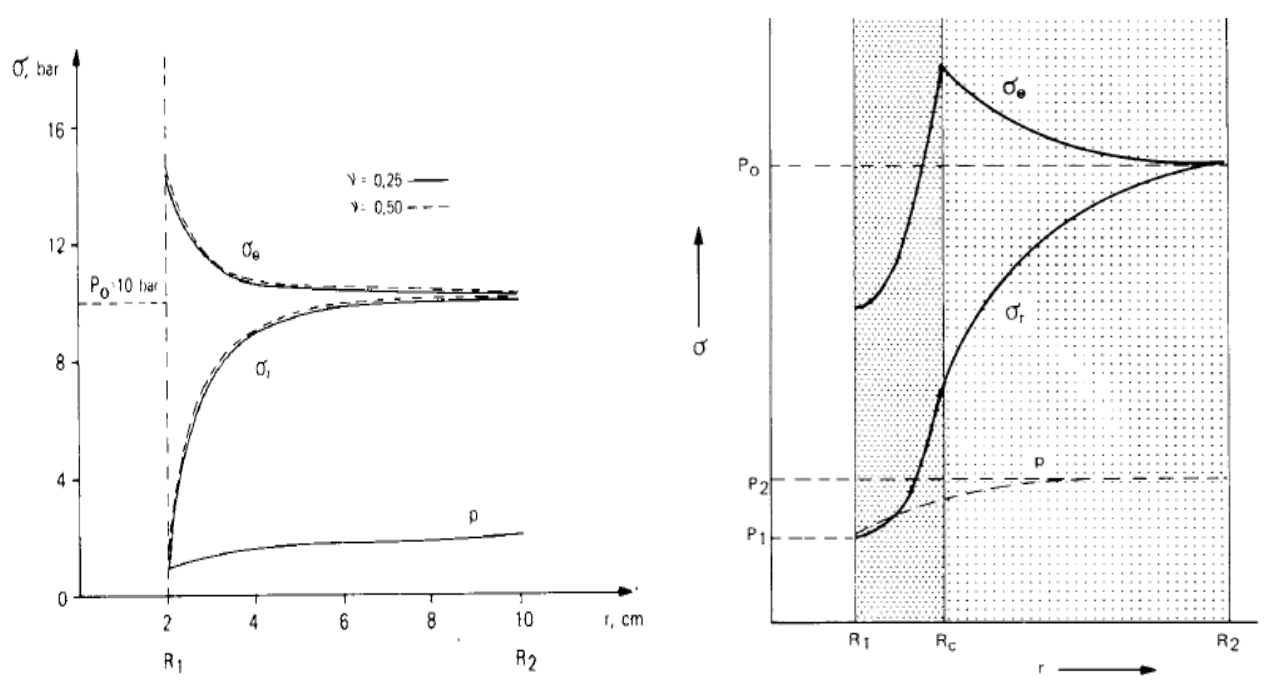

Fig 2.1: Stress profiles in radial direction

(a) Prior to failure (b) After failure (Bratli and Risnes, 1981)

It can be seen from the equation that higher stress contrast and lower cohesion induce a larger radius of damaged zone. If the denominator of the equation approaches zero because of low permeability, high viscosity, or high flow rate, the radius of the plastic zone could extend infinitely. When the boundary of the plastic zone increases and encounters a physical boundary, the sand arch can no longer hold its shape and will fail.

Sand arch failure can occur due to a different mechanism driven by tensile failure on the face of the cavity. Tensile failure occurs when the pore pressure gradient on the cavity face exceeds the radial stress gradient on the cavity face as illustrated by the relationship:

$$
\left(\frac{d p}{d r}\right)_{r=r_{c}}>\left(\frac{d \sigma_{r}}{d r}\right)_{r=r_{c}}=\frac{4 S_{\mathrm{o}} \tan \varphi}{r_{c}}
$$

The radial stress gradient on the cavity face is governed solely by mechanical parameters. 
The only parameter that depends on the fluid flow is the pore pressure gradient. If permeability reduction occurs due to fines migration, the pore pressure gradient increases and tensile failure is more likely to happen. This sand arch model was intentionally idealized to avoid numerical calculations. However, it provides valuable insights into fundamental relations that form the basis of current day sand production models. In addition, the analytical model allows for a quick calculation of perforation tip stability (since this can be approximated as a spherical cap).

\section{Stability of Wellbore / Perforation Wall}

Risnes and Bratli (1982) studied the failure of a cylindrical wellbore and derived stress solutions, starting from the equations of equilibrium in cylindrical coordinates (Fjær, 2008)

$$
\begin{gathered}
\frac{\partial \sigma_{r}}{\partial r}+\frac{1}{r} \frac{\partial \sigma_{\theta r}}{\partial \theta}+\frac{\partial \sigma_{z r}}{\partial z}+\frac{\sigma_{r}-\sigma_{\theta}}{r}+\rho f_{x}=0 \\
\frac{1}{r} \frac{\partial \sigma_{\theta}}{\partial \theta}+\frac{\partial \sigma_{r \theta}}{\partial r}+\frac{\partial \sigma_{z \theta}}{\partial z}+\frac{2 \sigma_{r \theta}}{r}+\rho f_{y}=0 \\
\frac{\partial \sigma_{z}}{\partial z}+\frac{\partial \sigma_{r z}}{\partial r}+\frac{1}{r} \frac{\partial \sigma_{\theta z}}{\partial \theta}+\frac{\sigma_{r z}}{r}+\rho f_{z}=0
\end{gathered}
$$

Symmetry in the $\theta$-direction and stress variations only in the r-direction with plane strain condition results in,

$$
\frac{d \sigma_{r}}{d r}+\frac{\sigma_{r}-\sigma_{\theta}}{r}=0
$$

Applying constant pore pressure, the stress solutions are written as, 


$$
\begin{gathered}
\sigma_{r}=\sigma_{h}-\left(\sigma_{h}-p_{c}\right) \frac{r_{c}^{2}}{r^{2}} \\
\sigma_{\theta}=\sigma_{h}+\left(\sigma_{h}-p_{c}\right) \frac{r_{c}^{2}}{r^{2}}
\end{gathered}
$$

Where $\sigma_{\mathrm{h}}$ is the far-field stress. Failure near the wellbore was described using a MohrCoulomb failure criterion as well and the stability analysis showed conditions under which the failed region would collapse. The most interesting result from comparing spherical and cylindrical cavities is that the spherical cavity tends to be stronger by a factor of two. Hence, under the same stress and flow conditions, the likelihood of tensile failure of the perforation wall is greater than the failure of the tip assuming the same material properties. This prediction agrees with many experimental observations from sand production tests that show that the perforation tip, although plastified and disaggregated, tends to produce less sand than the perforation wall.

Morita (1989) acknowledged that shear and tensile failure contribute to the instability of the perforation tunnel and tip. Major factors such as well pressure, in-situ stress, flow rate, permeability, fluid viscosity, rock deformation, and strength characteristics were identified. From an operational perspective, cyclic loading (shut-in), transient flow, and multi-phase flow are considered to be the major causes of sanding. A notable concept in his work was the idea of a normalized drawdown pressure gradient.

$$
g_{p n}=\left.r_{c} \frac{\partial p}{\partial r}\right|_{r=r_{c}}
$$

This parameter has been widely used in the industry to evaluate tensile failure. Another publication highlights the error of analytical models due to the simplification of the 
failure mechanism, the stress/strain relation, and the assumption of uniform modulus, strength, in-situ stress, and permeability around the cavity. It was suggested that these sources of error could add up to a significant deviation from actual sanding results. A good evaluation of model assumptions prior to using the results from the model is needed. For example, the stress anisotropy is pronounced in the field and this affects the failure envelope, hence sanding characteristics of formation. It is generally acknowledged that the onset of failure occurs at a lower stress level for higher stress anisotropy and this must be taken into a consideration.

A newer perspective on sand production was introduced by Veeken (1991). He concluded that any decision on sand control methods must be based on a good understanding of sand production. An overview of appropriate lab tests and field tests was introduced, and the integration effort for all the methods was suggested to create an efficient tool for sand production predictions. Tronvoll (1997) asked the question whether sand production was a result of mechanical failure or hydrodynamic erosion. Experiments revealed that material went through post-failure weakening. A major source of substantial sand production was attributed to the hydrodynamic forces due to fluid flow in spite of its relatively small magnitude compared to the strength of the rock. Therefore, weakening of the material was identified as a prerequisite for sand production. Van den Hoek et al. (2000) introduced a new study on failure modes of cavities. Using the normalized drawdown pressure gradient and shear failure stress, a comparison of dominant initial failure mechanisms was made. The conclusion was that medium to large holes such as a wellbore always failed in compression. The material failure point was dependent only on 
the threshold value of effective stress. Small cavities such as perforations could fail in tension due to extreme pore pressure. Smaller cavities were found to have "high" resistance towards shear failure. Therefore, the role of fluid flow in the initial failure was negligible and was only effective in producing sand after the onset of the failure. Consequently, a majority of recent work in sanding prediction have adopted sanding criteria on hydrodynamic forces acting on weakened or damaged regions near wellbores or perforations.

Willson (2002) non-dimensionalized formation stresses with material strength based on a thick-walled cylinder test and petrophysical parameters to portray the sanding potential. An additional factor called the "sand production boost factor" was introduced to account for massive sanding during water production. The model showed an empirical relationship between non-dimensionalized parameters, and it was able to predict sanding to a reasonable degree in the field. On the contrary, some focused on sand production only as a result of failure (Abass, 2002) to find limits for safe operations without sand.

In the 1990 's, large scale laboratory sanding tests were conducted, which focused on replicating field scale sand production to gain insight on the effect of some completion strategies (Kooijman, 1996). More detailed experiments and theories emerged to help understand each step of the sand production process and some of them will be presented in this thesis for experimental verification.

\section{Numerical Methods}

In addition to analytical models, Morita used the Finite Element Method (FEM) to predict sand production. The basic equations that govern these numerical simulations are, 
1. Mechanical equilibrium equations

2. Constitutive equations for the porous medium

3. Continuity equation for the fluid

4. Darcy's law

Details of these equations will be introduced in the next chapter.

Wang (2004), Pacheco (2009), and Chin and Ramos (2002) independently built fully coupled reservoir-geomechanics models for oil and gas wells. Papamichos (2001) presented a comprehensive analysis of volumetric sand production through experiments and finite element methods. To account for solid production, continuity of solids related the mass of sand to porosity by

$$
\frac{\dot{m}}{\rho_{s}}=\frac{\partial \phi}{\partial t}
$$

Mass generation due to erosion is

$$
\frac{\dot{m}}{\rho_{s}}=\lambda(1-\phi)\|q\|
$$

Permeability is altered due to porosity change using Kozeny-Carman equation

$$
k=k_{0} \frac{\phi^{3}}{(1-\phi)^{2}}
$$

Where :

$$
\begin{aligned}
& \mathrm{m}=\text { mass of sand produced per unit volume } \\
& \phi=\text { porosity } \\
& \rho_{\mathrm{s}}=\text { solid density } \\
& \mathrm{q}=\text { flow rate }
\end{aligned}
$$


$\lambda=$ sand erosion coefficient

$\mathrm{k}_{0}=$ original permeability

\| $\|=$ norm of a vector.

The sand production coefficient was also coupled with plastic shear strain. When the formation material did not experience plastic shear strain, which signified a state before yield, the sand production coefficient was zero and no sand production occurred. As the intensity of plastic strain increased, a piece-wise linear equation of the sand production coefficient was given. When the plastic strain exceeds a critical value, the sand production coefficient remains the same as the upper limit of the value.

For the numerical simulations, the governing equations for fluid flow and mechanical behavior of rocks mentioned in the model formulation (equations 2.18-2.20) were given in finite element formulation to solve for the coupled mechanical-erosion problem. The authors further conducted experiments to determine the effect of confining stress and fluid flow rate. Results suggested that the sand production amount demonstrated a second-order polynomial relationship with increasing confining stress and flow rate. Numerical results for a few experimental cases were successfully replicated, but the parameters in the simulation required extensive calibrating with the experiments, which remains a shortcoming of the model.

Fjær (2004) suggested a similar model, but focused on creating an analytical solution. The rate of sand production is governed by critical flow rate $\mathrm{q}_{\mathrm{cr}}$, porosity $\phi$, and sanding coefficient $\lambda$ 


$$
\dot{m}=\lambda \mu \frac{(1-\phi)}{\phi^{3}}\left(q-q_{c r}\right)
$$

Porosity increases with time as expressed by

$$
\phi \approx \phi_{0}\left[1+4 \frac{\lambda \mu}{\rho_{s} \phi_{0}{ }^{4}}\left(q-q_{c r}\right)\left(t-t_{0}\right)\right]^{0.25}
$$

Where $t_{0}$ is the initial time, $\phi_{0}$ is initial porosity, $\mu$ is fluid viscosity. To account for intermittent sand production observed in the field and experiments, the authors set an arbitrary parameter called critical porosity that set a limit on the porosity value at which the damaged matrix cannot support itself and collapses. These attempts to generate an analytical solution resulted in more unknown parameters, making the model difficult to use in a predictive mode.

A similar approach was adopted by Detournay (2006) and was implemented on a numerical simulator package called FLAC. Mechanical properties including post-failure properties, onset of failure, erosion due to hydrodynamic forces and tensile failure were implemented in the model. As the authors pointed out in the conclusion, the model looks sound, but the parameters such as erosion onset coefficient and erosion rate coefficient relied heavily on experiments for calibration. The feasibility of gathering enough data for all the parameters is questionable in normal industry practice. Another sand production prediction model by Nouri et al. (2004) showed experiments and numerical simulations. Instead of relying on calibrations with sanding tests to verify the model, it had a stronger emphasis on mechanical properties of sand and applying a suitable constitutive model. Testing of material for moduli, strain rate, and plasticity was conducted to ensure that the 
numerical model received sufficient input for accurate results. Although there were no calibration constants with the model, obtaining such a large number of parameters from experiments would be a challenge in the industry because of the time and cost involved. Papamichos (2008) recently suggested a history matching of field and experimental results in his recent publication. It requires calibrations on parameters related to pore pressure gradient and stress, but it is simpler to use than many conventional models. Sandstones were classified into three different types. Using parameters relating rock failure, flow, and a calibration constant, a general form of the equation was presented

$$
M_{s}=f\left(a_{s}\left\langle\left(\frac{d p}{d r}\right)_{c}-\left(\frac{d p}{d r}\right)_{s}\right\rangle\left\langle\sigma_{n}\right\rangle^{4}, t\right)
$$

Where $a_{s}$ is a calibration constant, $M_{s}$ is the sand mass per cavity area, $(d p / d r)_{s}$ is the critical pore pressure gradient for sand production. Macauley bracket $<>$ takes a non-zero value only when the expression inside of the bracket is non-negative. $\sigma_{\mathrm{n}}$ is normalized excess stress

$$
\sigma_{n}=\frac{\sigma_{c}-\sigma_{s}}{\sigma_{s}}
$$

Subscript $\mathrm{c}$ indicates confining stress and $\mathrm{s}$ is the sanding initiation stress. Although calibrations cannot be done without sand production tests to get the sand initiation stress and sanding profile, it reduces the inconvenience of running different types of experiments to find the many parameters. Therefore, the model is gaining popularity in the industry because of its ability to match sand production, although the mechanism behind sanding is still not clearly understood. Based on this method, a 
comprehensive study on sanding prediction that spans from sand production to surface facility erosion was conducted (Han, 2009) and some predictions were made for field applications.

\section{EFFECT OF TWO-PHASE FLOW}

Two-phase behavior is of interest to the industry because it has been observed that high water cuts usually result in the onset of massive sanding. To understand this, several experiments have been conducted (Bruno 1996). From arching experiments, it was found that grains without mechanical cohesion were only held by capillary cohesion.

Bianco (2001), in a similar experiment, reached a conclusion that single phase flow did not contribute to increased sand production. When the water saturation exceeded a threshold value near the irreducible saturation, massive sand production occurred because capillary force among disaggregated particles was lost as shown in Fig 2.2.

Water also weakens rocks, and UCS tests for saturated samples clearly show the effect of water on strength.

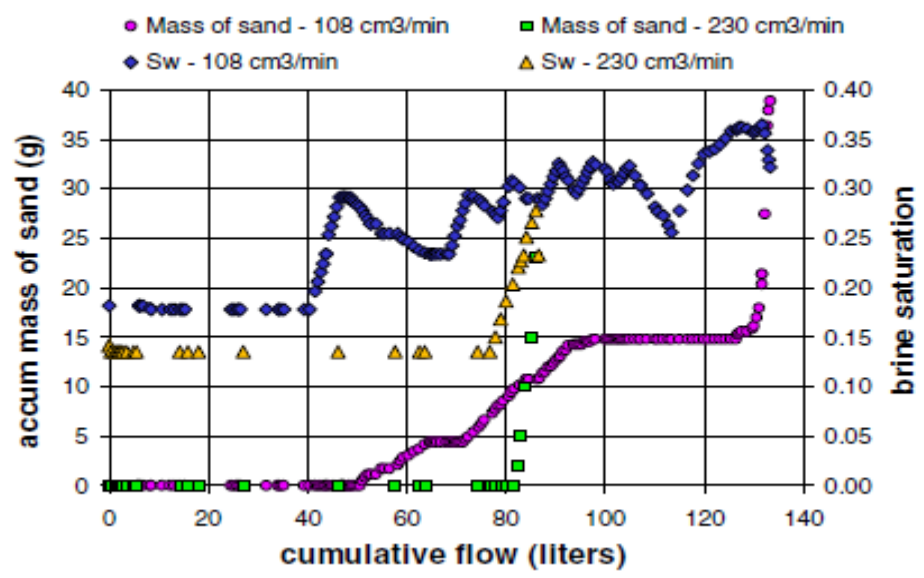

Fig 2.2: Sanding with increasing water saturation (Bianco, 2001) 
$\mathrm{Wu}$ (2006) found that the chemical composition of the cementation material affects the reaction of formation with water and this affects the sanding potential as well as the material strength of the rock. Bruno (1996) conducted experiments with a sand pack to study the effect of saturation on sand production. Observation showed that sand production required water saturation beyond irreducible water saturation as well. However, only a certain amount of sand was produced at one level of saturation due to the stabilization of sand grains. Higher saturation was required to trigger more sand production. Until now, the effect of water is known only in a qualitative sense through results derived from experiments and therefore requires more modeling work. Nouri et al. (2007) conducted experiments with sand packs made of coarse grain and fine grain to simulate expandable completion. Similar to other publications, they found that sanding characteristics vary the most in two-phase flow because of capillarity. It is difficult to incorporate capillary forces in pore-scale while simulating macroscopic phenomena in the reservoir due to the extent of information needed to understand capillary forces. Papamichos (2010) detected a water weakening effect in fully saturated Castlegate and Saltwash south core samples due to their failure at lower mechanical stresses compared to oil saturated cores or cores at connate water saturation. Cases showed that the mass of sand measured during the experiment was lower than the amount measured after the sample had completely dried. This suggests that the damaged zone was held by forces related to the fluid and when the fluid was lost during the drying process, more sand was produced. 
The same principles from water cut in producers can be applied to sanding problems in injectors (Vaziri, 2007). Water weakens the near wellbore region, making it more susceptible to failure. Injection also damages the formation. Combined with the high water saturation in the region, there is no capillary cohesion to keep the failed material from being injected during the injection period or produced during shut-in. With shut-in, water hammer and crossflow can cause sharp changes in fluid pressure and lead to more failure, sanding, and eventually plugging of the injectors.

\section{ChaPTer SuMmary}

Overall, there has been a continuous effort to predict sand production through analytical models of the perforation tip and wall, empirical models, numerical models, experiments, and field data. While most of the research work has generated relevant insights on sand production, a comprehensive model that can adapt to different experimental settings and to the field is not available because of one of two reasons: a lack of model sophistication or overly complicated models with excessive input requirements. Sanding is influenced by not only rock mechanics properties, but also by petrophysical properties that change over the course of production. This calls for a flexible and complete model with a quick run-time, a small and measureable set of parameters which provides reasonably accurate results. 


\section{CHAPTER 3: MODEL FORMULATION AND NUMERICAL SIMULATION}

\section{SAND PRODUCTION TIMELINE}

Before the start of the modeling process, it is important to understand the sanding process over the lifetime of a well. Fig 3.1 qualitatively illustrates the sanding rate over time and Table 3.1 provides a list of potential causes and solutions to sanding problems during the different stages of production.

1. During the transient flow period, large changes in drawdown occur. The amount of sand production varies with the rate of drawdown. If drawdown is not managed correctly, more than the allowable sand production can occur. Typically, damaged perforations are also cleaned up during this phase when the flow takes produced sand grains into the wellbore. The key to minimizing sand production during this transient period is to change drawdown gradually and reduce the pore pressure gradient near the wellbore through the slower opening and closing of the choke.

2. Steady-state sanding usually refers to sand production during normal production operations. It is usually affected by two factors: drawdown and water breakthrough. Drawdown must be maintained to be under the maximum allowable drawdown. Although there is a debate about whether or not our estimates of the maximum drawdown are correct, it is absolutely critical not to risk sanding due to excessive drawdown. The onset of water production usually results in additional sand production. 
3. Depletion affects the reservoir pressure. As hydrocarbons are recovered the pore pressure gradually decreases. This causes the effective stress in the formation to increase. Consequently, more failure occurs and sand production is more likely to be triggered. Depletion can be prevented with good pore pressure maintenance, but there is a compromise between this and risking massive sanding caused by water breakthrough.

4. Water breakthrough is often inevitable due to an aquifer or water injection. When water breaks through, the formation strength significantly decreases because of the loss in capillary cohesion between grains and possible chemical reactions with the cementation material. The effect of capillary cohesion can be significant in damaged areas near the wellbore. In many cases, an increase in water-cut signals a large amount of sand production. It is not possible to prevent water from being produced, but the use of better completion techniques such as inflow control device (ICD) and controlling the water front profile can delay sanding caused by water. Eventually it may be necessary to implement a sand control strategy that will deploy either mechanical (sand screens or gravel packs) or chemical (sand consolidation resins) methods. 


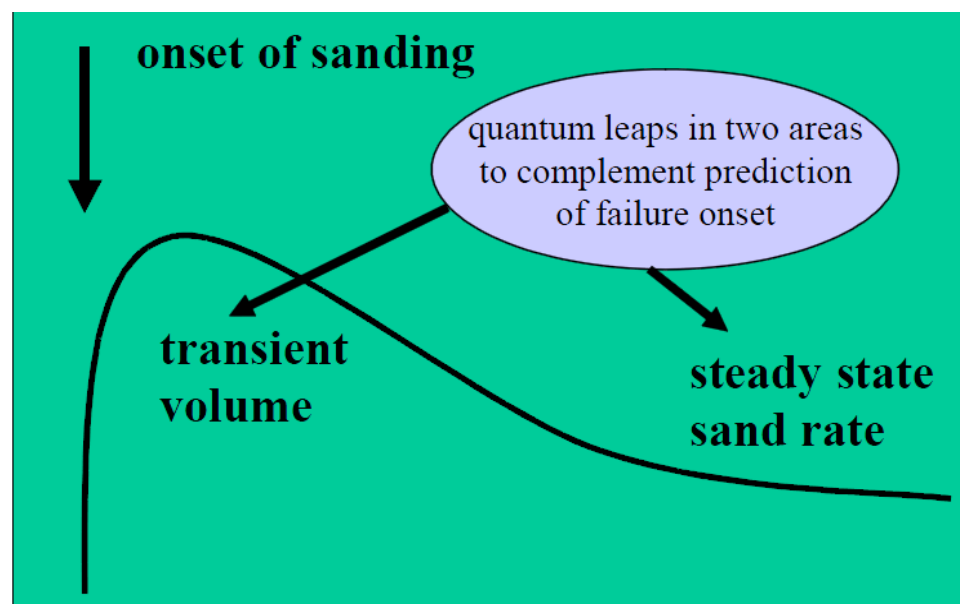

Fig 3.1: Sanding rate change over time (Palmer, 2003)

Table 3.1: Sand production timeline

\begin{tabular}{|c|c|c|c|c|}
\hline Stages & Transient & Steady-state & Depletion & Water \\
\hline \multirow{2}{*}{$\begin{array}{l}\text { Causes of } \\
\text { sand } \\
\text { production }\end{array}$} & $\begin{array}{l}\text { Change in } \\
\text { drawdown }\end{array}$ & \multirow{2}{*}{$\begin{array}{l}\text { Drawdown if } \\
\text { not properly } \\
\text { managed }\end{array}$} & \multirow{2}{*}{$\begin{array}{l}\text { Change in effective } \\
\text { stress due to pore } \\
\text { pressure reduction }\end{array}$} & \multirow{2}{*}{$\begin{array}{l}\text { Water-breakthrough } \\
\text { affecting formation } \\
\text { strength }\end{array}$} \\
\hline & $\begin{array}{c}\text { Clean-up of } \\
\text { damaged zone }\end{array}$ & & & \\
\hline $\begin{array}{l}\text { Sand } \\
\text { production } \\
\text { amount }\end{array}$ & Medium & Low & Medium & High \\
\hline \multirow[t]{2}{*}{ Solutions } & $\begin{array}{l}\text { Gradual } \\
\text { drawdown } \\
\text { change }\end{array}$ & Rate control & $\begin{array}{c}\text { Pressure } \\
\text { maintenance }\end{array}$ & ICD \\
\hline & \multicolumn{4}{|c|}{ Consolidation } \\
\hline
\end{tabular}

One convincing remedy that can encompass all the issues throughout the life of the well is consolidation treatment. It is a resin-based system that could be injected to increase the UCS of the near wellbore region, where failure and sand production mostly occur. The treatment can be conducted at any time during the life of the well, reducing 
the cost of completions. However, it is to the best interest of operators to identify the best window for the treatment.

Although solutions for different phases of sand production are quite clear, their impacts are not well known. Since an oilfield operation does not always favor sand-free

rates due to financial reasons, the risk of sanding must be assessed to find how much sand would be produced under certain operating conditions. Due to the lack of predictive modeling ability, this leads to a situation where solutions (mitigation) to sanding are not precisely applied, and the completion designs evaluate only the UCS of the formation. Consequently, a competent sand production model that is practical and accurate for operations is required.

\section{Three STeps to SAND Production}

Sand production observed on the surface occurs as a series of three events that happen downhole (Refer to Fig 3.2).

\section{Formation failure}

In-situ stresses and pore pressure act on formation sands and under certain conditions, the criteria for failure are met. The presence of the wellbore and perforations causes a concentration of stresses near these cavities and deformation and failure can occur under certain well known conditions. It is important to recognize that sand failure does not automatically lead to immediate sand production, but it could be an indicator of future sanding.

\section{Sand erosion due to flow}


Damaged regions that have failed (meet the failure criteria) face additional stresses caused by pore pressure gradients. The process of sand erosion is essential for the sand to be removed from the failed region and entrained with the fluid.

\section{Sand transport}

Sand erosion detach sand grains into a perforation cavity or wellbore. Some of the grains are produced to the surface while others settle into the perforation tunnel or into the well rat hole. Modeling of this sand transport is crucial to quantitatively predicting the amount of sand produced at the surface. These estimates allow us to evaluate the amount of sand that is acceptable on the surface and safety concerns regarding erosion of facilities.

This thesis focuses on the first and second steps of sand production because they have the most impact and are not as well understood.

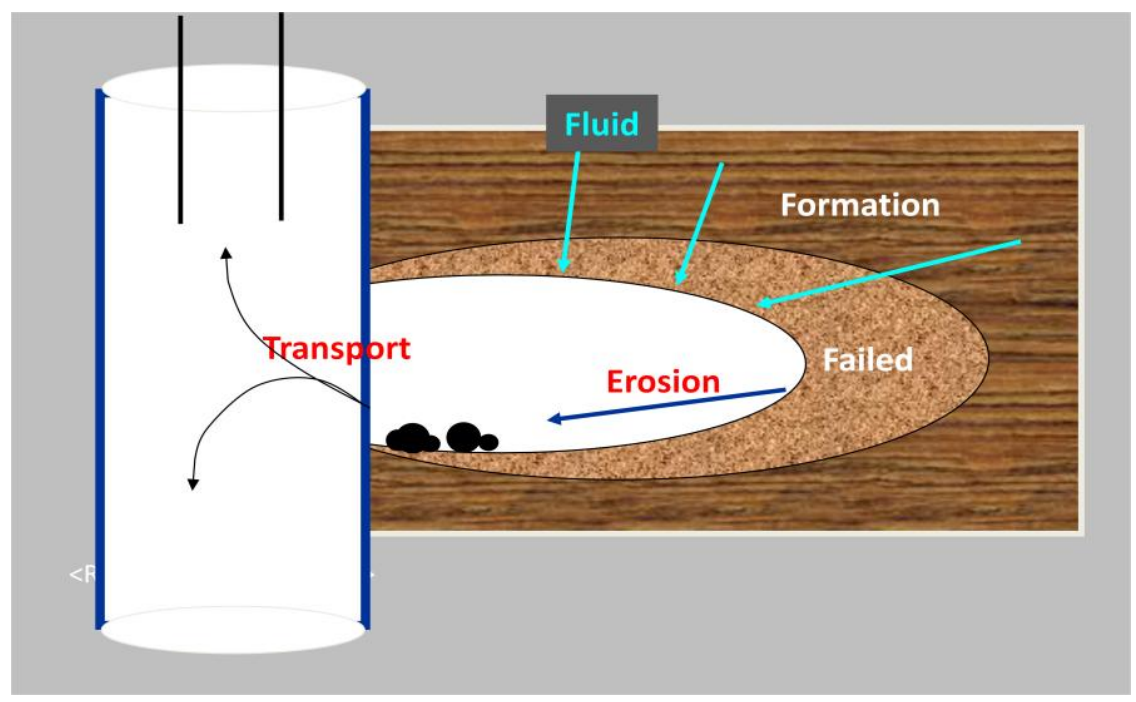

Fig 3.2: Sand production steps 


\section{FORMATION FAILURE}

There are different types of failure. The graphical representation in Fig 3.3 shows qualitatively what conditions cause each type of failure.

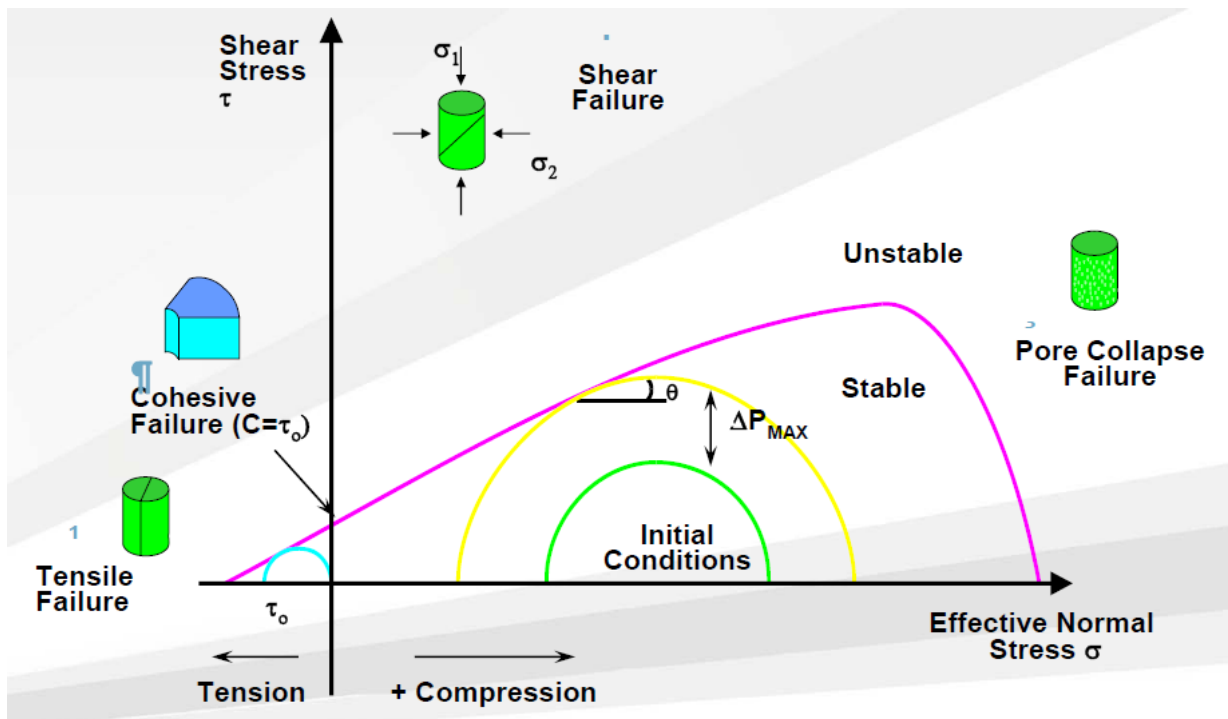

Fig 3.3: Illustration of modes of mechanical failure

Shear failure is one of the most prevalent modes of failure in the formation. There are many models that describe shear failure such as the Mohr-Coulomb and Griffith criteria. Graphically, the criterion is satisfied when the semi circle drawn by the applied normal stresses touches the failure envelope (the pink line in Fig 3.3). A Mohr-coulomb envelope can be obtained through a series of confined and unconfined triaxial tests. In cylindrical cavities, tangential stress can be expressed in terms of pore pressure, in-situ stress, and Poisson's ratio as the following,

$$
\sigma_{\theta}=2 \sigma_{h}-p_{w}-\frac{1-2 v}{1-v} \alpha\left(p_{0}-p_{w}\right)
$$


Where $v$ is Poisson's ratio, $\alpha$ is Biot's coefficient, and $p_{\mathrm{w}}$ is well pore pressure. Critical drawdown $p_{d}{ }^{c}$ can then be defined as:

$$
p_{d}^{c}=(1-v)\left(C_{0}-2\left(\sigma_{h}-p_{0}\right)\right)
$$

Where $\mathrm{C}_{0}$ is the UCS. From this relation, an increase in UCS or reservoir pressure can increase the critical drawdown, which is positive from an operations point of view. Fig 3.4 tells a similar story of formation failure dependence on reservoir pressure and drawdown. When the reservoir pressure is sufficiently high, allowable drawdown is also high. However, when the reservoir depletes and the effective stresses increase, the upper limit of drawdown disappears, meaning the formation will fail regardless of the drawdown value. It is important to note that the figure illustrates failure, not sanding. Even if the operating condition lies on the "sand production possible" region, actual sanding may not occur.

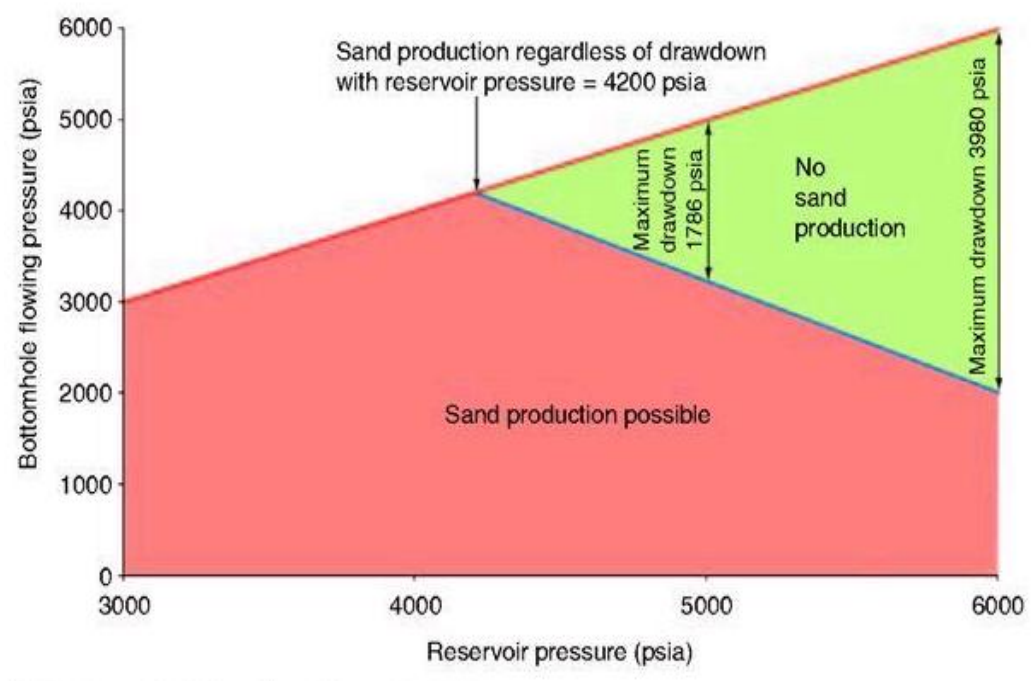

Fig 3.4: Dependence of failure on reservoir pressure and drawdown (Fjær, 2009) 
Tensile failure occurs when the tensile stress exceeds the tensile strength of the material. Normally, when the pore pressure gradient is high, effective stress near a cavity can become negative. When the effective stress exceeds the tensile strength of the material, tensile failure occurs. Bratli and Risnes (1981) indicated/recognized that once there is an onset of shear failure and sand arches form, their breakdown does not come from shear, but tensile failure.

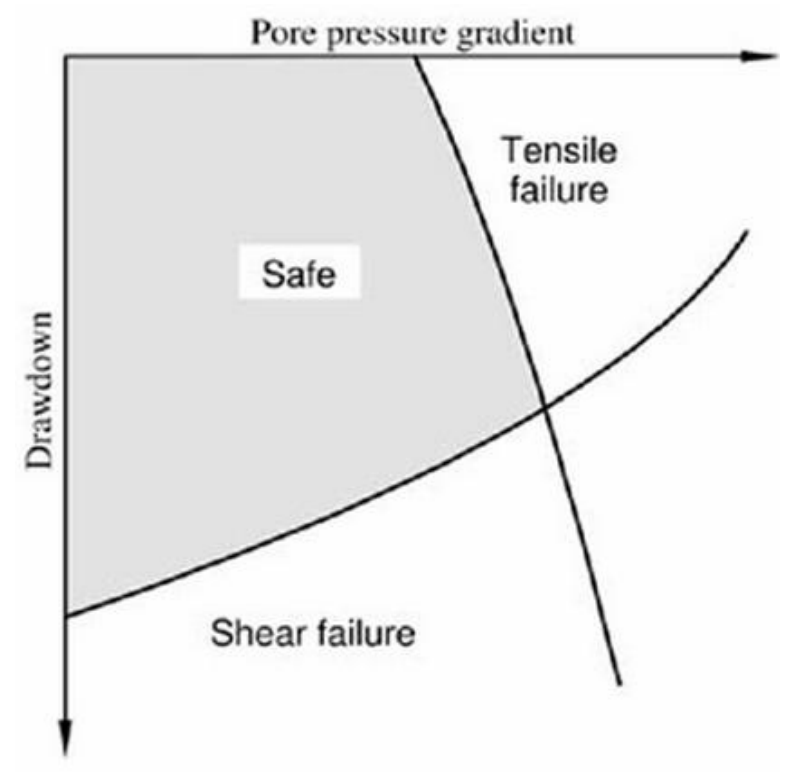

Fig 3.5: Failure envelope in relation to operating conditions (Fjær, 2009)

\section{FaILURe MeChanics}

In a paper (Yi, 2004) discussing the failure types and mechanisms, the authors created two models for sanding in a perforation tunnel or tip. One model defines sand production as an onset of shear failure. The other states that sand production occurs from shear failure followed by tensile failure. An interesting observation could be made from the field examples in Fig 3.6.and Fig 3.7 that show two different wells in which the 
failure models were applied. The shear + tensile failure model calculated allowable bottom-hole pressure values that were lower than the actual measurements by more than $2000 \mathrm{psi}$ (Fig 3.6a). The prediction was too optimistic and the well would have produced sand if the model result was applied in the field. The application of the shear only model, Fig 3.6b showed an improvement. In a different well (Fig 3.7), the opposite trend was observed for the two models. The shear + tensile model showed a better prediction of the bottom-hole pressure. These results imply that there is no single dominant failure mechanism and sand production can occur with either mechanism.
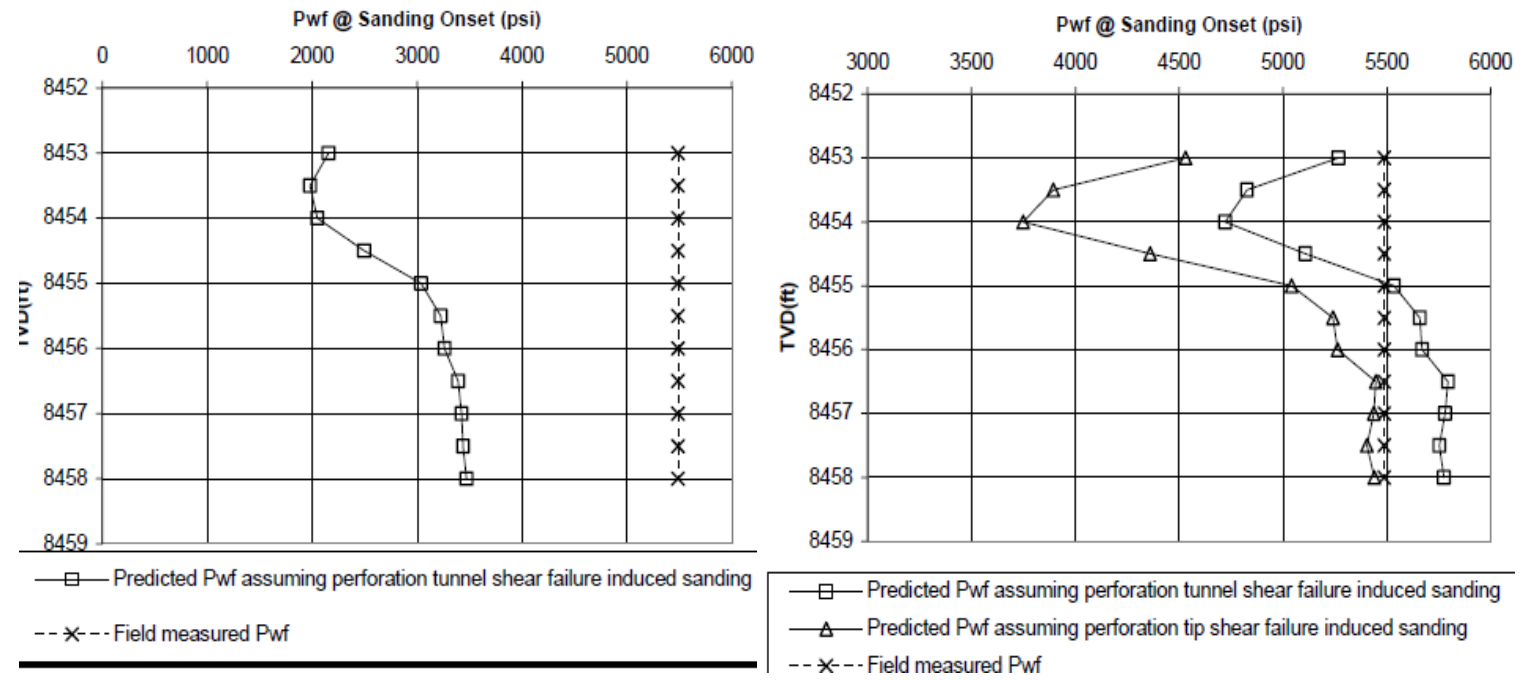

Fig 3.6: Bottom-hole pressure comparison in well A (Yi, 2004)

a) Shear + Tensile model b) Shear only model 


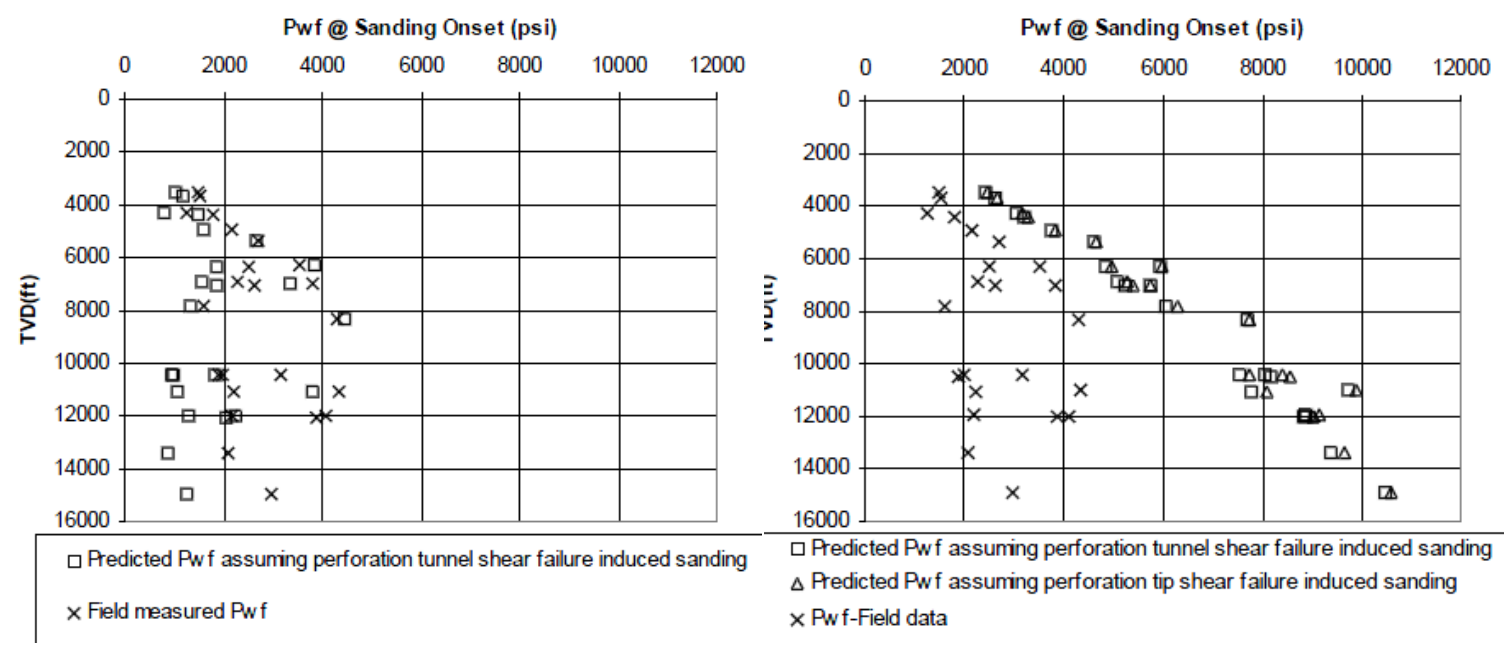

Fig 3.7: Bottom-hole pressure comparison in well B (Yi, 2004)

a) Shear + Tensile model b) Shear only model

\section{FORMULATION OF NUMERICAL MODEL}

Finite Lagrangian Analysis in Continuum in 3D (FLAC3D) uses a finite difference scheme to model mechanical systems and flow in a porous medium. While there are many types of packages available for solid mechanics, FLAC3D offers built-in feature to couple geomechanics with fluid flow in its calculation. The coupled response from the software allows users to implement models to understand the behavior of the formation in response to fluid flow. The numerical framework provided by FLAC3D was used to conducting the mechanics and flow calculations and to apply the appropriate boundary conditions. The physics of the sand production problem was implemented within this framework. This thesis will touch upon only the fundamental equations used in our application and a few specific details of the software for the relevant topics. Readers should refer to the FLAC3D Manual for more specific numerical details. 


\section{Grid and Boundaries}

A gridblock, (also refered to as a zone), is a basic unit in the simulation generated by the built-in meshing feature in FLAC3D. It can be a polyhedron of any type that is made up of several tetrahedra. A tetrahedron has 4 nodes and a constant strain-rate with linear velocity field. The vertices of a gridblock are called grid points. Gridpoints and gridblcks store different information regarding values of variables and boundary conditions. For mechanical boundary conditions, stress or displacement can be applied. For fluid boundaries, constant pore pressure, specific discharge, and leaky conditions can be applied. Keywords such as gridpoint, gridblock, and face increase the flexibility in specifying boundary conditions. Users must be fully aware of these choices and requirements to correctly impose boundary conditions. For instance, displacement and velocity are properties of gridpoints, whereas stresses and material properties are attributed to gridblocks. One exception is pore pressure. It is calculated on gridpoints, but FLAC3D conveniently converts it into pore pressure by volumetric averaging. Assigning properties of gridblocks is needed to apply constitutive models. By using several range keywords, the assignment can be done efficiently and easily.

\section{Governing Equations}

Equations must be able to describe the mechanical and fluid behavior of the rock.

The momentum balance (or the condition of mechanical equilibrium) is,

$$
\begin{aligned}
& \frac{\partial \sigma_{i j}}{\partial x_{j}}+\rho g_{i}=\rho \frac{d u_{i}}{d t} \\
& \rho=(1-\phi) \rho_{s}+\rho_{w}
\end{aligned}
$$


Where $\rho$ is the bulk density, $\rho_{s}$ is the density of solid phase and $\rho_{w}$ is the density of the liquid phase. The compatibility equation can be written as,

$$
\varepsilon_{i j}=\frac{1}{2}\left[\frac{\partial u_{i}}{\partial x_{j}}+\frac{\partial u_{j}}{\partial x_{i}}\right]
$$

Biot's poroelastic theory couples the behavior of rock matrix and fluid. Biot's coefficient is a measure of change in pore volume relative to the bulk volume of the matrix

$$
\alpha=1-\frac{K}{K_{s}}
$$

Where $\mathrm{K}$ is the drained bulk modulus of the porous medium and $\mathrm{K}_{\mathrm{s}}$ is the solid bulk modulus. Biot's modulus is defined by

$$
M=\frac{K_{u}-K}{\alpha^{2}}
$$

Where, $\mathrm{K}_{\mathrm{u}}$ is the undrained bulk modulus of the material. Mshows the contrast between bulk modulus and fluid modulus

$$
M=\frac{K_{w}}{\phi+(\alpha-\phi)(1-\alpha)\left(\frac{K_{w}}{K}\right)}
$$

Where $K_{w}=\frac{\Delta P}{\Delta V_{w} / V_{W_{w}}}$ is the fluid bulk modulus and $\phi$ is porosity.

Pore pressure and matrix deformation are related with a constitutive equation

$$
\frac{1}{M} \frac{\partial p}{\partial t}=\frac{\partial \zeta}{\partial t}-\alpha \frac{\partial \varepsilon}{\partial t}
$$


Where $\varsigma$ is the variation of fluid content (variation of fluid per unit volume of porous material) and $\varepsilon$ is the volumetric strain. The constitutive law for elastic materials can be written as:

$$
\frac{\partial \sigma_{i j}}{\partial t}+\alpha \frac{\partial p}{\partial t} \delta_{i j}=2 G \frac{\partial \varepsilon_{i j}}{\partial t}+\left(K-\frac{2}{3} G\right) \frac{\partial \varepsilon_{k k}}{\partial t} \delta_{i j}
$$

Where $\sigma_{i j}$ is the stress tensor, $\mathrm{K}$ is the bulk modulus and $\mathrm{G}$ is the shear modulus.

The variation of fluid content can be found using the fluid mass balance equation

$$
\frac{\partial \zeta}{\partial t}=-\frac{\partial q_{i}}{\partial x_{i}}+q_{v}
$$

Where and $\mathrm{q}_{\mathrm{v}}$ is the volumetric fluid source intensity.

Darcy's law describes the flow in a porous medium.

$$
q_{i}=-\frac{k_{i j}}{\mu} \frac{d\left(p-\rho_{w} x_{i} g_{i}\right)}{d x_{j}}
$$

Where $\mathrm{k}_{\mathrm{ij}}$ is the permeability tensor, $\mathrm{x}_{\mathrm{j}}$ is displacement vector, $\mathrm{q}_{\mathrm{i}}$ is the specific discharge vector, $\mathrm{p}$ is pressure in the pores, $\rho_{w}$ is the fluid density, $\mathrm{g}_{\mathrm{i}}$ is the gravity vector. It is important to remember that FLAC only uses the mobility coefficient which is the ratio between the permeability and viscosity. Anisotropic permeability can be specified. During a simulation run, the equilibrium equation is first called upon with forces or stresses based on the boundary condition. This produces velocities and displacements and results in stresses by using a constitutive equation as shown in Fig 3.8. 


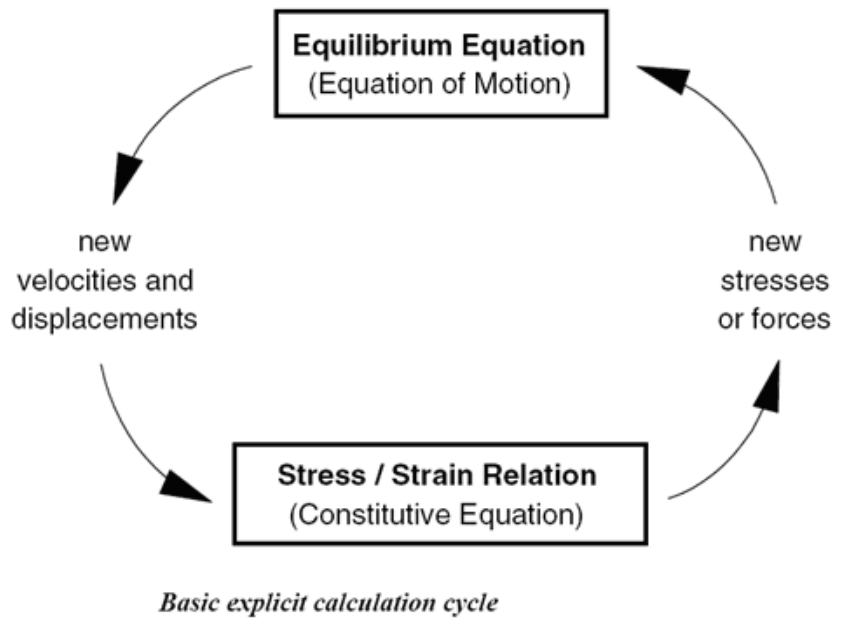

Fig 3.8: Calculation cycle (explicit) in FLAC3D (User Manual, FLAC3D 3.1)

\section{Time Scales}

Time scales, both mechanical and fluid, are an important consideration for the optimization of runtime. In FLAC3D, mechanical equilibrium is said to occur instantaneously while the fluid characteristic time is dependent on several parameters. The characteristic time for mechanical equilibrium is given by

$$
t_{c}^{m}=\sqrt{\frac{\rho}{K_{u}+4 / 3 G}} L_{c}
$$

Where $\mathrm{G}$ is the shear modulus, $\rho$ is the matrix density, and $\mathrm{L}_{\mathrm{c}}$ is the characteristic length (i.e., the average dimension of the medium).

The characteristic time for the fluid diffusion process is:

$$
t_{c}^{f}=\frac{L_{c}^{2}}{c}
$$

Where $\mathrm{c}$ is the diffusivity, defined as 


$$
\begin{aligned}
c & =\frac{k}{\frac{1}{M}+\frac{\alpha^{2}}{K+4 G / 3}} \\
& \left.=\frac{k}{\frac{\phi}{K_{w}}+\frac{1}{K+4 G / 3}} \quad \text { (if } \alpha=1\right)
\end{aligned}
$$

The time step for a coupled calculation is proportional to the square of the smallest gridblock size and the inverse of the product of mobility and Biot's modulus. Since the smallest gridblock length (in the direction of flow) is in the order of a few millimeters, the time step is in the order of $10^{-6}$ seconds. Sanding tests usually last for minutes and hours, and it is not realistic to run a coupled simulation for the desired simulation time. One might consider increasing the gridblock size to increase the time step, but this is not an option because the spatial resolution of our sanding model would decrease.

To overcome this problem, a mixture of calculation modes is used. These modes must be carefully selected to account for any physical phenomena happening throughout transient and steady-state sanding. Due to the nature of experiments applying mechanical or flow perturbations through an increase in stress or pore pressure, a transient behavior is often expected. This transient behavior is captured through coupled mechanical and flow calculations. On an experimental scale, the transient time is short and reaching equilibrium with coupled calculations is feasible. Once the transient period is over, we conduct a steady-state calculation where the mechanical and flow calculations can be uncoupled and a flow profile can be established. This de-coupling takes away the time dependence and the simulation is driven by a change of boundary conditions in the 
experiment. These changes can be tied to time through the experimental procedure. To summarize, the model is solved in transient mode (pore pressures and stresses changing with time) every time there is a change in the applied stresses or pore pressures. Once steady - state is achieved the stabilized pore pressure profile can be used directly in the mechanical equilibrium equation (with no time dependence).

\section{SAND ERosion: The Importance ON SAND Production}

Sand failure is not sufficient to define sanding, but it provides critical information on new stress states and material properties. Erosion of the failed sand must occur after failure for sand production to occur.

From experimental studies, it is clear that flow is essential for sand production; since failure alone does not lead to sand production. As shown in Fig 3.9, a correlation between drawdown and sand production can be seen from an experiment. As the axial strain increases due to increasing axial stress, the non-linear behavior of the stress vs. strain curve indicates that the sample has experienced failure. Sanding starts at a point with non-zero drawdown. After the onset of sanding, whenever drawdown drops to zero, cumulative sand production plateaus, suggesting that there is no sand production taking place. Hence, it is fair to assume that drawdown, which induces flow, is directly related to sand production after initial sanding. When axial strain is beyond $3 \%$, drawdown below $50 \mathrm{kPa}$ induces as much sand as in the part where axial strain is less than $3 \%$ and drawdown is over $100 \mathrm{kPa}$. This clearly shows the effect failure has on sanding. More extensive damage and failure make erosion easier due to hydrodynamic forces. 


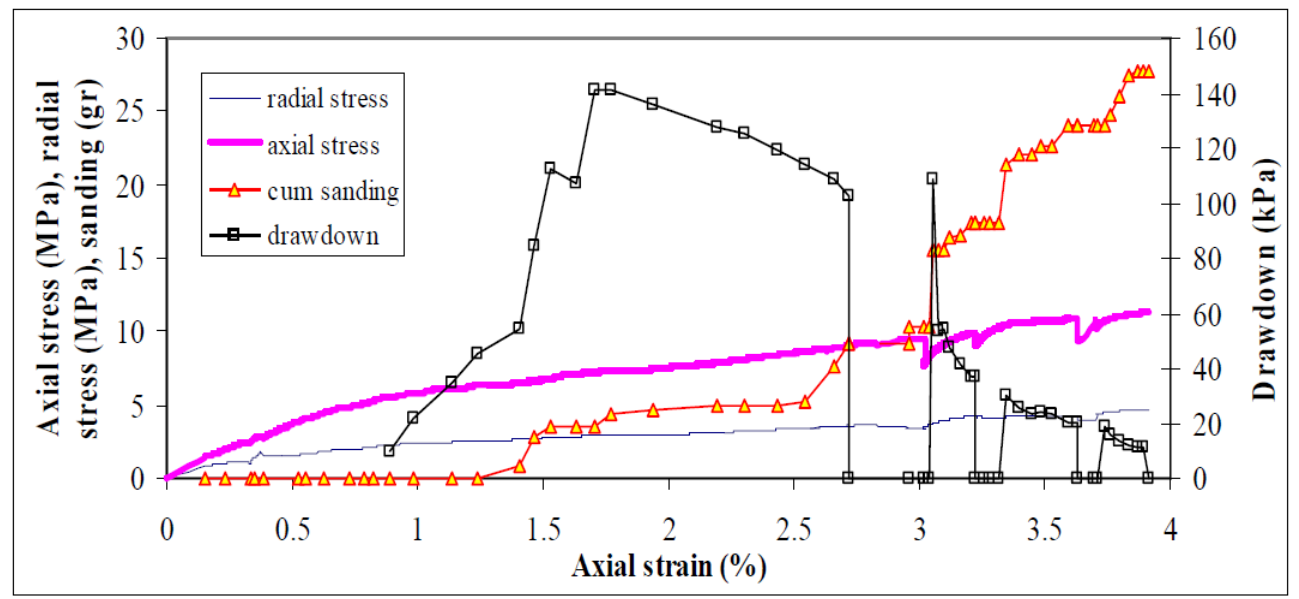

Fig 3.9: Sanding profile from (Nouri, 2004)

\section{EROSION CRITERIA}

Sanding criteria can be divided into tensile failure induced sanding and shear failure with hydrodynamic erosion. These components follow the general observation from literature reviews.

1. Tensile failure occurs when the radial pore pressure gradient exceeds the radial stress gradient on the cavity surface. It is assumed that this causes immediate sand production if there is any flow.

2. Shear failure occurs according to the Mohr-Coulomb failure criterion and leads to a weakening of the matrix. Given a sufficient pore pressure gradient, sand grains detach from the matrix.

Fig 3.10 represents a diagram of forces that are broken down in different directions to understand the net force acting on each block. When any gridblock on the cavity face fails, the erosion criterion is invoked and a force balance is conducted on each 
grid. For simplicity, this section will describe only the force balance in the r-direction as Fig 3.10 shows only one open face in the r-direction. In the real implementation of the numerical code, a force balance is conducted in all directions with open faces.

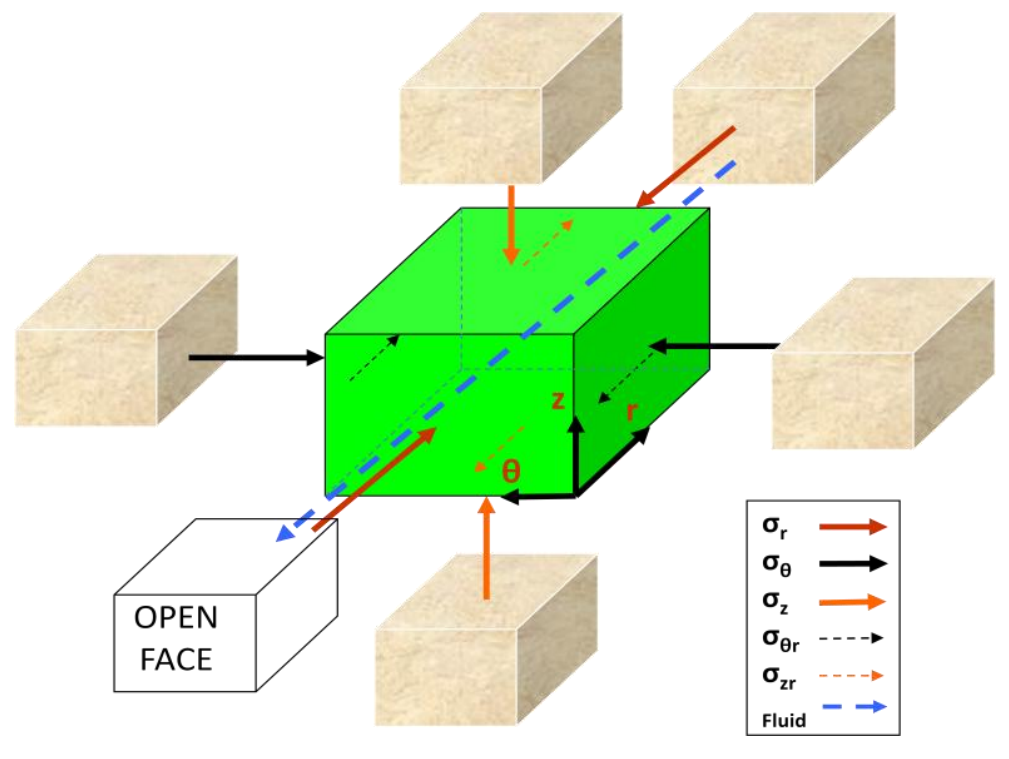

Fig 3.10: Stresses acting on a gridblock with one face open

A gridblock experiences two types of forces while it is in the formation: frictional resistance and hydrodynamic forces. The frictional resistance is the force that holds the failed gridblock in the formation. Equation (3.16) shows the resistance force which is calculated in the positive r-direction. Commonly, frictional forces between gridblocks are characterized by vertical and tangential stresses and friction coefficient $\mu_{\mathrm{f}}$. The Figure also shows forces contributed from radial and shear stresses. Depending on the sign of the resistance force, it can act in favor of either production (-) or resistance $(+)$. Note that the area of the faces in the radial direction is not uniform. It gradually increases towards the inside of formation due to the structuring of the gridblock in this sample case. The 
dimension of each side in $\mathrm{r}$ and $\mathrm{z}$-direction are L. Although the dimension of the block in $\theta$-direction gradually increases as $\mathrm{r}$ increases, its average length is set to $\mathrm{L}$ as well for the purpose of illustration. The resistance (due to friction) can be written as,

$$
F_{r}=\left.\left(A_{r} \sigma_{r}\right)\right|_{r=L} ^{r=0}-\left.A_{\theta} \sigma_{\theta r}\right|_{\theta=0} ^{\theta=L}-\left.A_{z} \sigma_{z r}\right|_{z=0} ^{z=L}+\mu_{f}\left(\left.A_{\theta} \sigma_{\theta}\right|_{\theta=0}+\left.A_{\theta} \sigma_{\theta}\right|_{\theta=L}+\left.A_{z} \sigma_{z}\right|_{z=0}+\left.A_{z} \sigma_{z}\right|_{z=L}\right)
$$

Where $\mathrm{A}$ is the area of gridblock normal to the direction of subscript and $\sigma$ is stress. The hydrodynamic force acts parallel to the flow and is generated by the pore pressure difference between the inner and exposed faces of the grid,

$$
F_{f}=\left.\left(A_{r} p\right)\right|_{r=L}-\left.A_{r}\right|_{r=0} p_{w}
$$

Where $\mathrm{p}$ is pore pressure and $\mathrm{p}_{\mathrm{w}}$ is pore pressure on the open face which is equivalent to the wellbore pore pressure. A positive hydrodynamic force indicates the force acting in the direction of flow. The erosion criteria states that when the hydrodynamic force overcomes the frictional resistance force, the sand will be eroded,

$$
F_{f}>F_{r}
$$

When the gridblock of interest is eroded, the produced sand volume is assumed to be,

$$
V_{s}=V_{z} \phi
$$

Where $\mathrm{V}_{\mathrm{s}}$ and $\mathrm{V}_{\mathrm{z}}$ are sand and gridblock volume respectively. $\phi$ is porosity.

This erosion mechanism is coded into FISH programming language in FLAC3D. It is invoked by the simulation during the run when necessary. Finding the forces on each face of a gridblock using a numerical simulator is not trivial because stress values given from FLAC3D are volumetrically averaged at the centroid of the gridblock. Six stress states for every gridblock are output by FLAC3D in Cartesian coordinates. Since the 
geometry of wellbore and perforation are better described and handled in cylindrical coordinates, a coordinate transformation in radial, tangential (hoop), vertical, and corresponding shear stresses is required. Therefore, a post-processing of the states in FLAC3D must be carried out to calculate stresses and pore pressure to apply the erosion criteria. The following equations show the transformation of stresses into cylindrical coordinates.

$$
\begin{gathered}
\sigma_{r}=\frac{1}{2}\left(\sigma_{x}+\sigma_{y}\right)+\frac{1}{2}\left(\sigma_{x}-\sigma_{y}\right) \cos 2 \theta+\sigma_{x y} \sin 2 \theta \\
\sigma_{\theta}=\frac{1}{2}\left(\sigma_{x}+\sigma_{y}\right)-\frac{1}{2}\left(\sigma_{x}-\sigma_{y}\right) \cos 2 \theta-\sigma_{x y} \sin 2 \theta \\
\sigma_{z}=\sigma_{z} \\
\sigma_{r \theta}=\frac{1}{2}\left(\sigma_{y}+\sigma_{x}\right) \sin 2 \theta+\sigma_{x y} \sin 2 \theta \\
\sigma_{r z}=\sigma_{x z} \cos \theta+\sigma_{y z} \sin \theta \\
\sigma_{\theta z}=\sigma_{y z} \cos \theta-\sigma_{x z} \sin \theta
\end{gathered}
$$

All normal and shear stresses used in these calculations are extracted from the FLAC3D software for each zone.

The assumptions in the model include:

1. The friction coefficient is an empirical parameter that controls erosion and is expected to depend on grain size, and mineralogy.

2. Porosity does not change over the course of erosion process, hence no permeability change takes place as gridblocks are removed. This assumption can be relaxed but this would introduce additional empirical parameters in the model. The model presented here is a continuum model that offers considerable computational efficiency compared to discrete element models (Cundall, 1979). Each 
gridblock contains many sand grains. Because gridblock size is typically large compared to grain size (100 grains), sanding in the model always occurs in discrete jumps and this tends to lower the resolution of the sanding profile. However, it is common to observe sand production in discrete increments in experiments. As mentioned in the previous chapter, many models incorporate changes of porosity in the sand production mechanism due to the detachment of grains and pore-space enlargement. Time is also associated with this erosion process because it does not occur instantaneously. Modeling these creates additional parameters such as critical porosity and time dependence of erosion. Therefore, the suggested erosion model is not associated with any porosity changes or evolution with time, and once a gridblock meets the erosion criteria, it is immediately produced. 


\section{Simulation Procedure}

Simulation in FLAC3D is conducted through a series of steps shown in Fig 3.11.

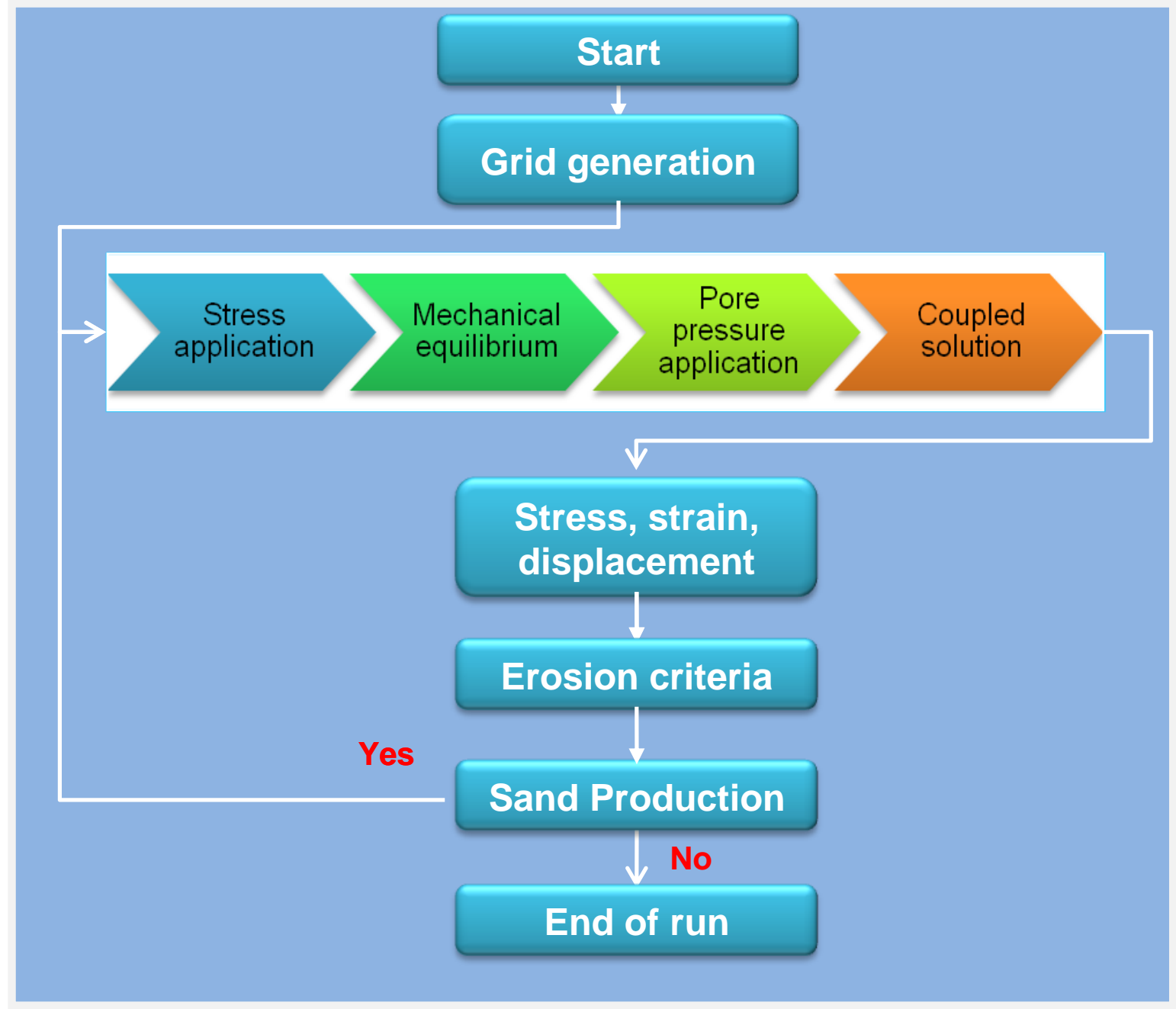

Fig 3.11: Simulation Flow Chart

The steps involved are:

1. Grid generation

2. Assignment of mechanical and flow properties to grids 
3. Changes made to stresses or fluid pressures at the boundaries.

4. Start the transient and steady-state calculation loop for sand production,

a. Solve mechanical and flow equilibrium equations

b. Apply erosion criteria

c. Eliminate gridblocks that have failed and are eroded

d. Apply boundary condition to boundary gridblocks

5. End of simulation

Steps through 1-2 are executed once to create an initial state. Assuming there is only a one-time perturbation, Step 4 is executed repeatedly until there is no more sand production. Upon satisfying the erosion criteria in Step 4b, grids with sand production are eliminated and boundary conditions are assigned to the newly exposed cavity face.

\section{ChAPTER SUMmary}

A model was formulated for sand failure and erosion in this chapter. Shear failure is identified to be a dominant failure type occurring in cavities. Failure results in the weakening of the near wellbore region. Subsequently, hydrodynamic forces applied by the pore pressure gradient become sufficient in some parts of the cavity face to cause erosion. Equations used in the model reflect this physical understanding. Tensile failure can occur in some cases and this leads to immediate sand production, regardless of the hydrodynamic forces. The following chapter presents three distinct sets of experiments and the model generated results are compared with these lab experiments conducted under controlled and well defined conditions to verify the capability of the model. 


\section{CHAPTER 4: EXPERIMENTAL VERIFICATION}

\section{INTRODUCTION}

The sand production model presented in the last Chapter needs to be tested against experimental and field results. This chapter contains comparisons of the model with three different sets of experiments obtained from the literature. Results show that the sanding model generates sand production plots that provide a reasonable match with the experiments.

\section{AdVANTAGES OF EXPERIMENT}

Reproducing in-situ conditions is nearly impossible in the lab environment. Scaling the experiment to the field is often challenging. However, field sand production profiles are very difficult to obtain due to the lack of measurements taken. Although lab experiments are not an exact representation of sand production in the field, they are accessible and they provide a controlled environment within which to analyze and understand sand failure. They provide the most direct and useful tool for verification of sanding models especially with regard to the scope of failure and erosion (excluding sand transport). These experiments are also used as a primary means of evaluating the sand risks in the field in some cases.

\section{GENERAL EXPERIMENTAL SETUP}

A typical experiment requires a hollow cylinder core, which has been perforated or drilled on one or two open ends. Hollow cylinder is meant to simulate the wellbore or the perforation, depending on the ratio between the outer and inner diameters. Some researchers choose to use popular outcrops such as Castlegate, Saltwash South, and 
Saltwash North. Manufactured samples with known grain-size distribution are other options for core samples. Prior to the sanding test, mechanical properties such as UCS and various elastic moduli of the sample are measured. This thesis will cover some of methodologies for parameter gathering in the next chapter.

A triaxial cell is the most popular setup for sanding experiments. Fig 4.1 shows a typical triaxial cell used in sand production tests. Axial stress can be applied through a hydraulic piston. Confining pressure is applied using a rubber jacket that surrounds the core sample. Fluid can also be introduced using a fluid port, normally placed at the top or bottom of the cell. Some choose to have vertical flow while others achieve radial flow by using a high-permeability membrane between the rubber jacket and the sample. The cell has an open outlet that allows produced material to pass through. Monitoring of sand is done by measuring the weight of sand collected at the outlet. Periodically obtaining data is crucial to generating a sanding profile.

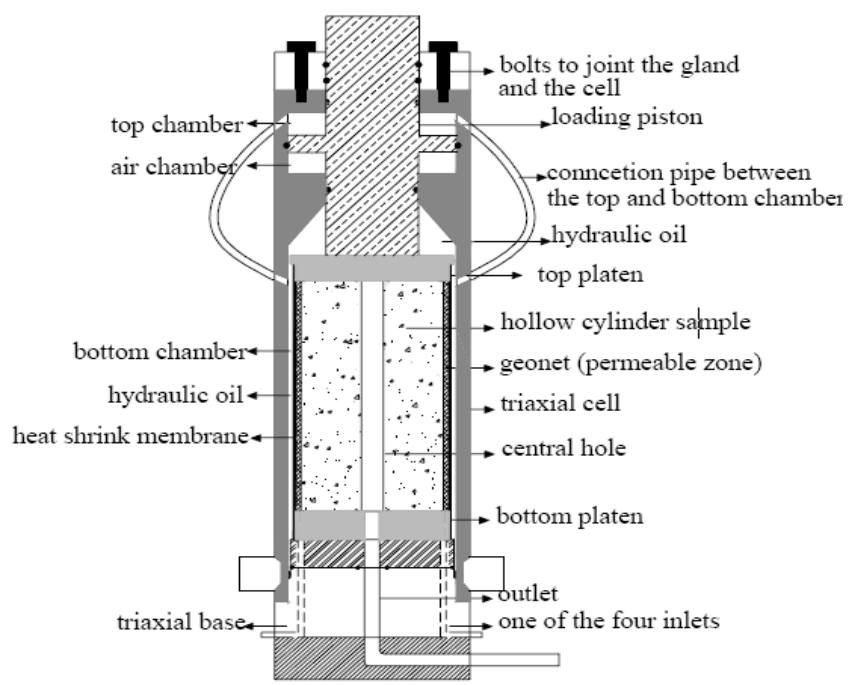

Fig 4.1: Experimental setup (Nouri, 2004) 
Table 4.1: Summary of material properties for experiments

\begin{tabular}{|c|c|c|c|}
\hline Parameters & Case 1 & Case 2 & Case 3 \\
\hline Permeability (md) & 3600 & 500 & 690 \\
\hline Porosity & 0.36 & 0.3 & 0.22 \\
\hline Viscosity (cp) & 1 & 5 & 1.7 \\
\hline Young's modulus (MPa) & 400 & 800 & 4830 \\
\hline Poisson's ratio & 0.438 & 0.15 & 0.35 \\
\hline Friction angle (degree) & 40 & 50 & 38 \\
\hline Cohesion (kPa) & 2600 & 273 & 2380.5 \\
\hline Tension $(\mathrm{kPa})$ & 310 & 27.3 & 69 \\
\hline
\end{tabular}

\section{CASE 1: NOURI (2004)}

Nouri (2004) provides an excellent set of data for sand production experiments.

Measurements are provided for the non-linear parameters for the material used. This allows for a more accurate input of the change of material properties. Beyond yielding, material behavior is governed by plasticity. Plastic strain and hardening govern the postfailure behavior of the material. In general, the change in friction angle is described by

$$
\begin{gathered}
\sin \varphi^{*}=2 \frac{\sqrt{\left(\varepsilon^{-p} \varepsilon^{f}\right)}}{\varepsilon^{-p}+\varepsilon^{f}} \sin \varphi \text { for } \varepsilon^{-p}<\varepsilon^{f} \\
\sin \varphi^{*}=\sin \varphi \text { for } \varepsilon^{-p}>\varepsilon^{f}
\end{gathered}
$$

Where $\varphi^{*}$ is the mobilized friction angle, $\varepsilon^{-\mathrm{p}}$ is the plastic strain, $\varepsilon^{\mathrm{f}}$ is a constant, and $\varphi$ is friction angle.

Cohesion changes with plastic strain as well,

$$
c^{*}=c e^{\left[-\left(\frac{\varepsilon^{-p}}{\varepsilon^{f}}\right)^{2}\right]}
$$

The relationship between mobilized dilatancy angle and plastic strain is defined by 


$$
\sin \psi^{*}=\frac{\sin \varphi^{*}-\sin \varphi_{c v}}{1-\sin \varphi^{*} \sin \varphi_{c v}}
$$

Where $\varphi_{\mathrm{cv}}$ is a parameter calculated by the friction angle $\varphi$ and the dilatancy angle $\psi$.

$$
\sin \varphi_{c v}=\frac{\sin \varphi-\sin \psi}{1-\sin \varphi \sin \psi}
$$

These changes in material properties affect sand production, as shown in Table 4.2. Yet, this kind of data availability is far from the norm. Industry practice usually calls for measuring only the very basic elastic parameters.

Table 4.2: Material property changes during shear hardening (Nouri, 2004)

\begin{tabular}{|c|c|c|c|c|c|c|c|}
\hline Shear-hardening parameter (\%) & $\mathbf{0}$ & $\mathbf{0 . 3}$ & $\mathbf{3 . 0}$ & $\mathbf{5 . 0}$ & $\mathbf{7 . 0}$ & $\mathbf{1 0 . 0}$ & $\mathbf{2 0 . 0}$ \\
\hline Cohesion (kPa) & 2600 & 814 & 568 & 300 & 115 & 10 & 10 \\
\hline Friction angle high confining stress (deg) & 0.0 & 11.0 & 28.1 & 31.8 & 33.0 & 34.0 & 34.0 \\
\hline Dilation (deg) & 0.0 & 0.0 & 0.0 & 3.2 & 6.3 & 13.8 & 13.8 \\
\hline
\end{tabular}

The experimental setup shown in Figure 4.1 was used to measure the mass of sand produced as the increasing axial and confining stresses were applied. Different flow rates were used under each stress condition. While the experiment is running, neither the stresses nor the drawdown profiles are constant as shown in Fig 3.9. While the axial stress profile increases slowly, drawdown fluctuates a lot. Data points on stresses and drawdown were extracted from Fig 3.9 and entered into the simulator. Since the core was a hollow cylinder, pore pressure and mechanical stress values were set to atmospheric pressure on the cavity surface. Drawdown was specified by adding the drawdown value to the atmospheric pressure. Confining stress was applied on the outer boundary and the 
axial loading to the top of the sample while the bottom of the sample was fixed. Shearhardening parameters in Table 4.2 were specified by using the strain-softening constitutive model in FLAC3D and the friction angle variation at high confining stress was allowed to occur at confining stresses exceeding 3.5MPa.

The comparison between the simulation and experimental results shown in Fig 4.2 generally shows good agreement. The set of parameters used in the simulations are shown in Table 4.1. Note that all of these parameters were measured experimentally and these measured values were used in the simulations. No attempt was made to change the parameters to curve fit the experimental data. Note that sand production is plotted versus the axial stress, not axial strain. This representation is more relevant in understanding the sanding phenomenon because stresses are often thought to be a major driver for sanding and strain is only a byproduct of the stresses. At about $8.3 \mathrm{MPa}$, sanding initiated both in the experiment and the simulation. Also, sanding profiles agreed well with experimental values with no adjustable parameters. The sand production amounts at the end of the test 
show a remarkably similar result with only a few grams difference.

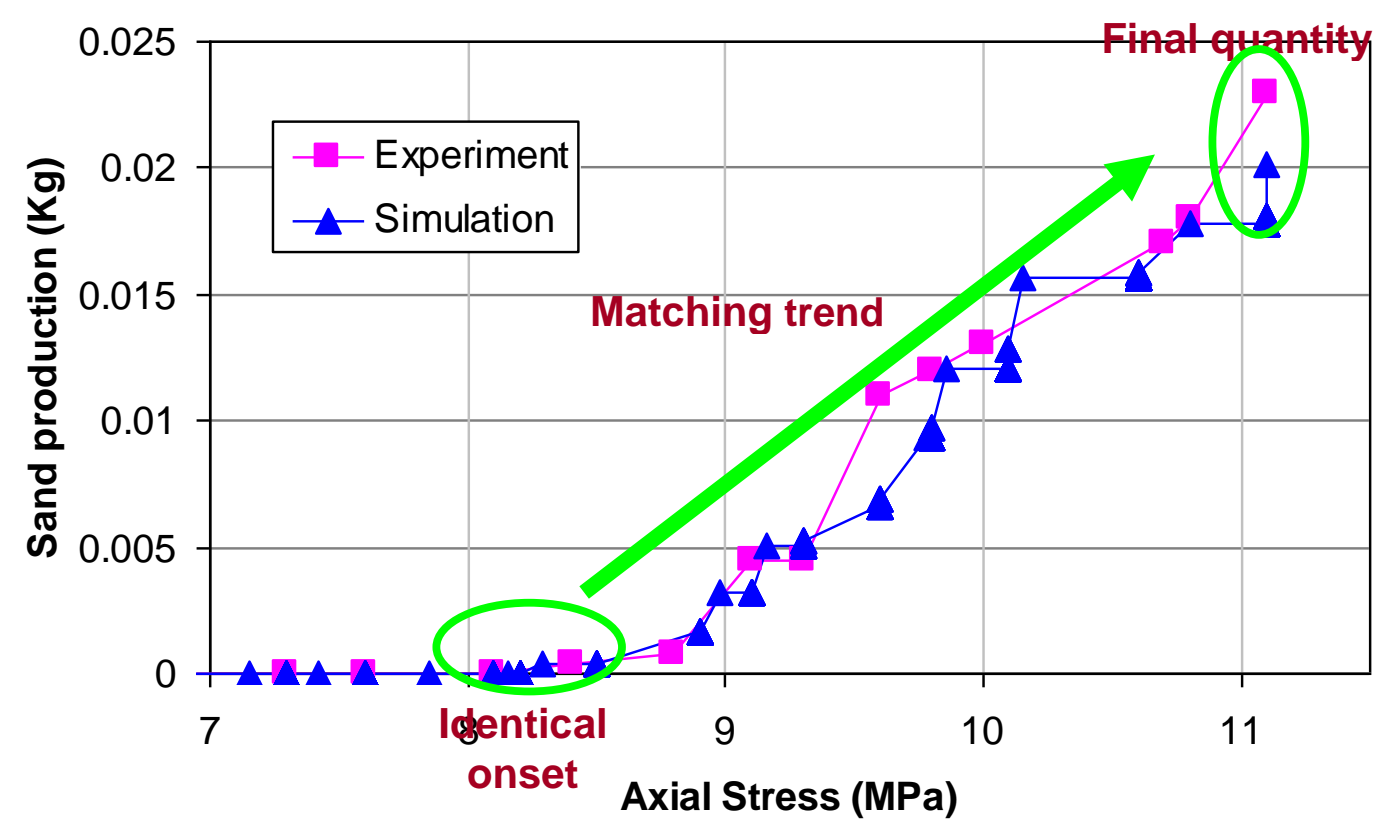

Fig 4.2: Sand production profile from experiment and simulation for varying axial stress

\section{Case 2: Papamichos (2001)}

Papamichos's work mostly focused on finding how external stresses and fluid flow affect sanding. Only basic parameters such as permeability, porosity, and oil viscosity were given, which is far from sufficient to run any simulator. Hence, another publication (Tronvoll, 1997) was used to find possible values of elastic moduli of samples used to simulate this experiment. From triaxial tests, the core sample showed some non-linear behavior, however it could not be quantified and, therefore, was not included in the simulation.

Using the hollow cylinder core and the triaxial cell, confining stress was applied on top, bottom, and around the cell. Fluid was introduced radially. At a given confining 
pressure, the flow rate increased from $0.25 \mathrm{~L} / \mathrm{min}$ to $3 \mathrm{~L} / \mathrm{min}$ over a period of approximately $8000 \mathrm{sec}$. After the maximum flow was achieved, it was reduced back to $0.25 \mathrm{~L} / \mathrm{min}$ and the confining pressure was increased by $0.5 \mathrm{MPa}$ until the final confining stress reached $15 \mathrm{MPa}$. However, when the confining stress reached 13MPa, there was massive sanding because of global specimen failure.

The sand production profile in Fig 4.2 shows that the amount of sand produced at a confining stress of $7.5 \mathrm{MPa}$ was less than the amount produced at $11 \mathrm{MPa}$. As external stresses increase the general trend is for the amount of sand produced to increase. The trend of increasing sand production over time occurs because the flow rate is increasing with time (as described above). Higher flow rates lead to higher sand production.

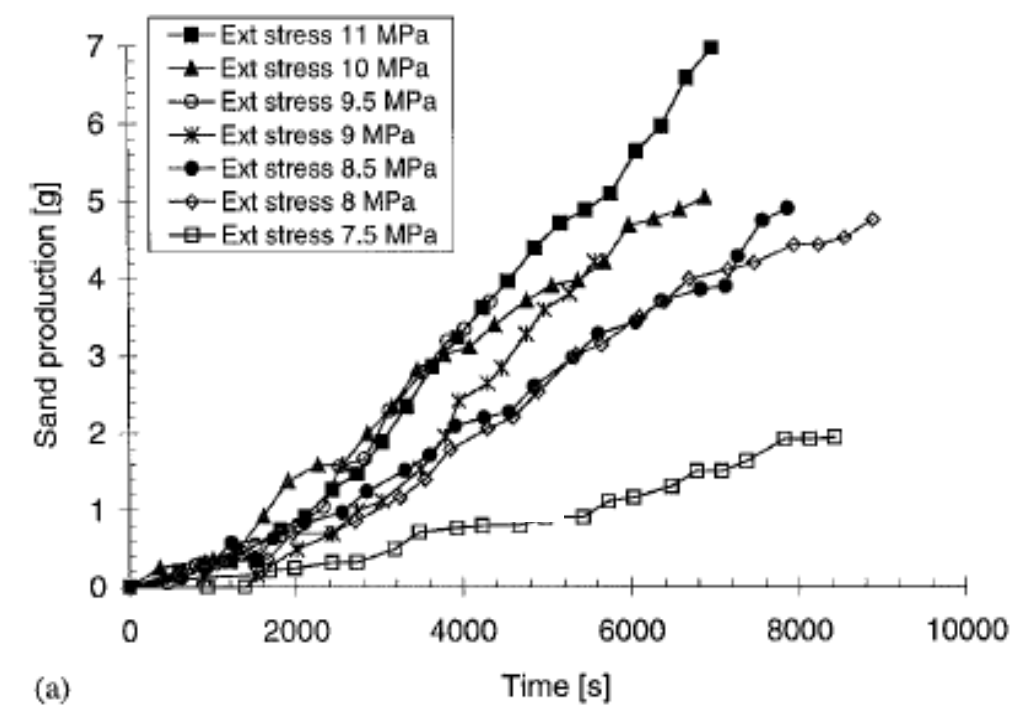

Fig 4.3: Sand production comparison at different confining stress (Papamichos, 2001) In the simulation, there was no way of imposing atmospheric pressure on the cavity face because the injection rate was given instead of the far-field pore pressure. 
This led to applying zero stresses on the cavity face.

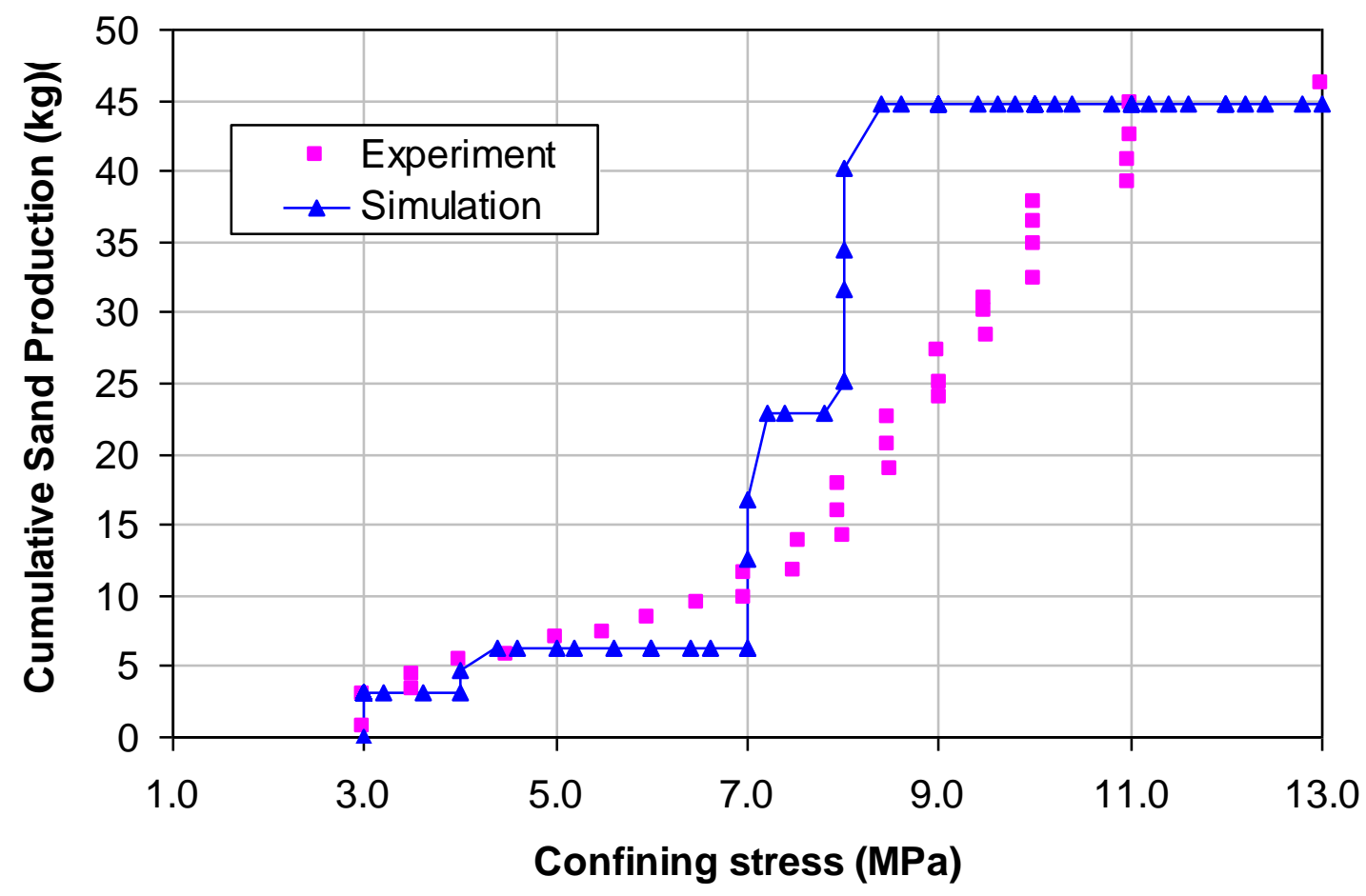

Fig 4.4: Sand production profile

The entire experiment was replicated in a simulation conducted up to $13 \mathrm{MPa}$ confining stress. The sanding trends from the simulation match the experiment from 3 to $7 \mathrm{MPa}$ very well. Sand production started to diverge from the experiment under higher confining stresses. One possible reason for this divergence could be the lack of porosity and permeability changes in the model. Yet the end value of the simulation matched the experiment very well. The tensile strength of the material was adjusted to get a good match with the experiment. 


\section{CASE 3: Chin \& Ramos (2002)}

A set of experiments was conducted by the authors who used Saltwash South (SWS) sandstone cores. The rock samples were 15 inches in diameter and 24 inches in length. They drilled a half-inch hole in the middle of each sample to represent a perforation with a round tip. Fluid was introduced from the bottom and side of the sample through a permeable membrane around the core. A pressure transducer was embedded 7 inches below the tip of the perforation to record fluid pressure. Because the pressure was not measured from the outside, it was difficult to find the actual boundary pore pressure. In addition, ranges were given for Young's modulus and Poisson's ratio, which were $1.0 \times 10^{5}$ to $7.0 \times 10^{5}$ and 0.11 to 0.35 respectively. These parameters were used in the bulk and shear modulus calculation. Such unreasonably wide ranges of values decreased the accuracy of the simulation. These sources of error could cause a disparity between experiment and simulation results presented here.

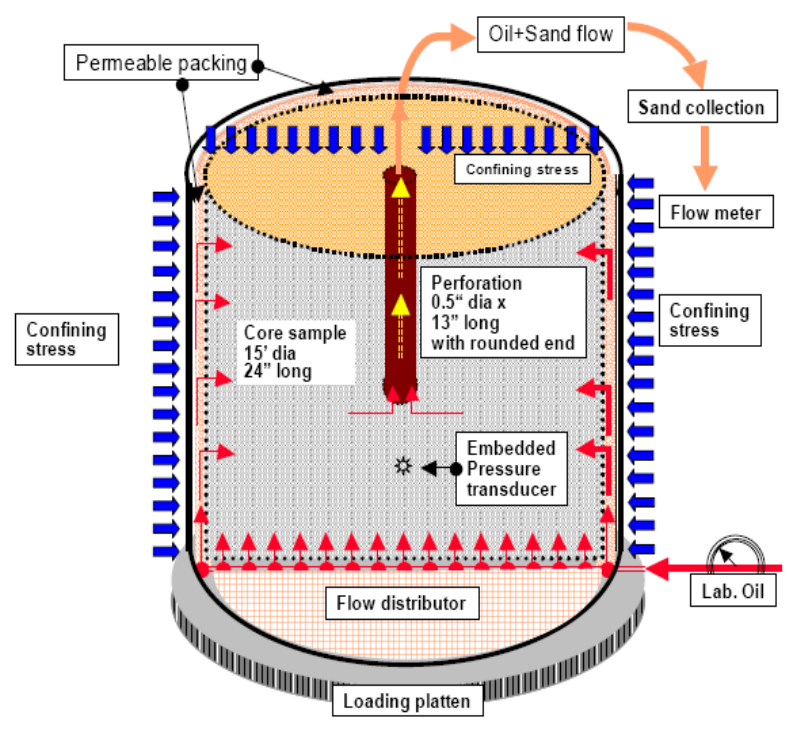

Fig 4.5: Experimental setup (Chin, 2002) 
There were four test schemes used in the publication. Only three of these that used a $1.7 \mathrm{cp}$ fluid viscosity were simulated. Test $\# 1$ focuses on the effect of confining stress on sanding. While keeping the fluid pressure constant, stress was gradually increased from 2000 to 7000 psi. Post-test \#1 observations indicated that "the perforation was enlarged to 1.5 " diameter, but its length was essentially unchanged. The hole was surrounded by disaggregated material about 2.5 " in diameter. The tip contained a spherical bulb of disaggregated sand 3.5" in diameter...." From this statement, it was assumed that the perforation tip did not affect the sanding characteristics and that the simulation geometry may be approximated as a cylinder. After Test \#1 was simulated in the simulator, the extent of the damage was confirmed in Fig 4.6. The non-blue region represents failed zones, in which the dimensions of failure and cavity were slightly larger than what was observed.

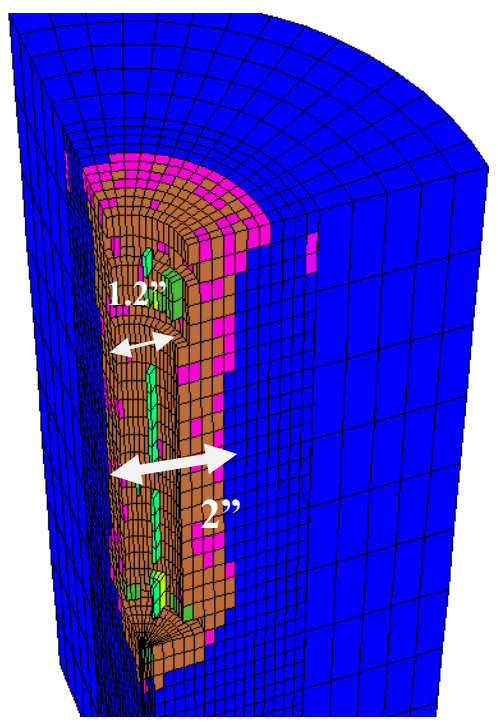

Fig 4.6: Failed material (in non-blue) and dimensions of failure after Test \#1 
Fig 4.7 shows cumulative sanding versus confining stress and cumulative flow. While the simulation demonstrated a quick increase in cumulative sand production and stabilization at a higher confining stress, the experiment had a linearly increasing trend in cumulative sanding with higher confining stresses. At $4500 \mathrm{psi}$, the difference between the experiment and the model is at a maximum. Near the end of the test, there is massive production of sand. This generates comparable sanding amounts from the model and the experiment.

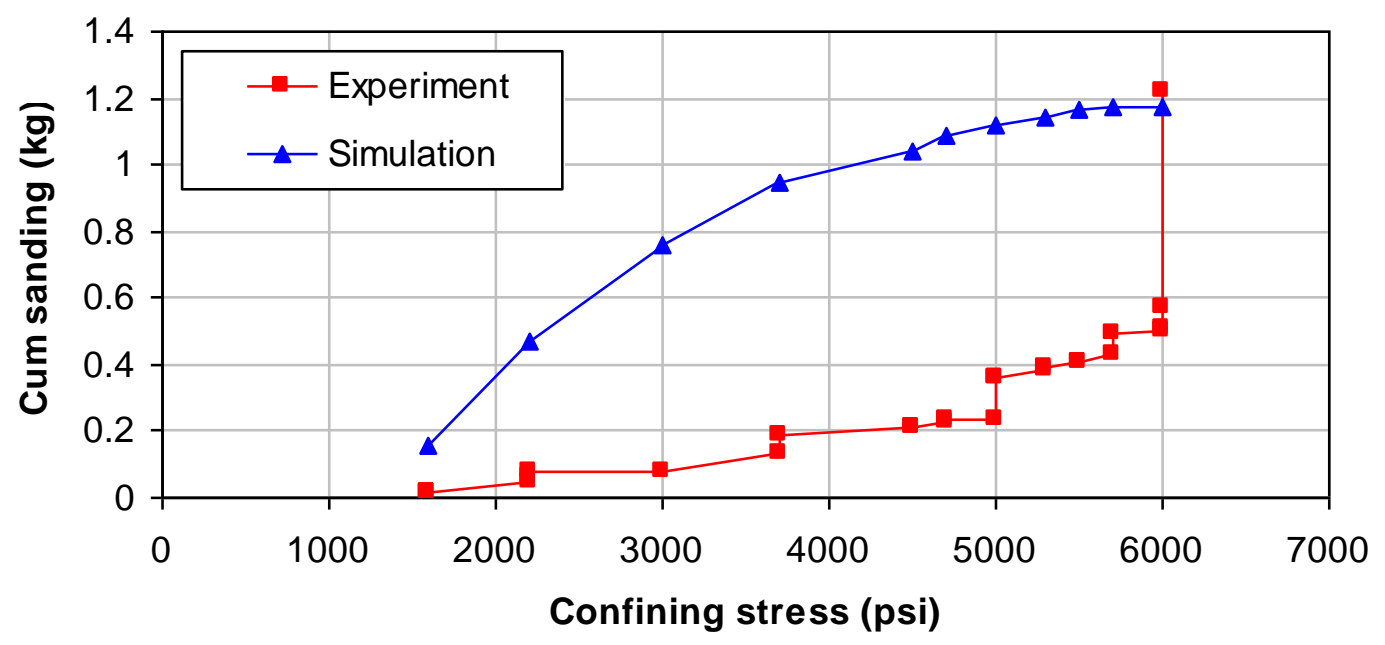

Fig 4.7: Sand production profile with cumulative flow and stress (Test \#1) Test \#2 was designed to see the effect of flow rate under two different confining stresses. During the test, the maximum flow rate achieved was $150 \mathrm{cc} / \mathrm{sec}$, which is higher than other tests by at least twofold. The early results show comparable results with the experiment. However, as the simulation progressed, a diverging pattern of sand production was observed. The model was able to capture neither the effect of stress change or flow rate. Massive sanding from near the perforation tip and the wall seems to 
be a probable cause of this discrepancy. It must be remembered that a large region of failure all around the perforation wall and tip was found in Test \#1. We can hypothesize that the failed region was able to withstand the flow rate, which was low and constant in Test \#1. In Test \#2, sharp increases in sanding were observed when there were stress increments during the experiment as shown in Fig 4.8. The very high rate of flow in Test \#2 could have caused an onset of massive erosion in the disaggregated region that enlarged whenever there was a stress increment, leaving very little damaged zone for any flow rate increase to affect sanding amount. Unfortunately, there was no observation of a post-test sample and the theory could not be confirmed.

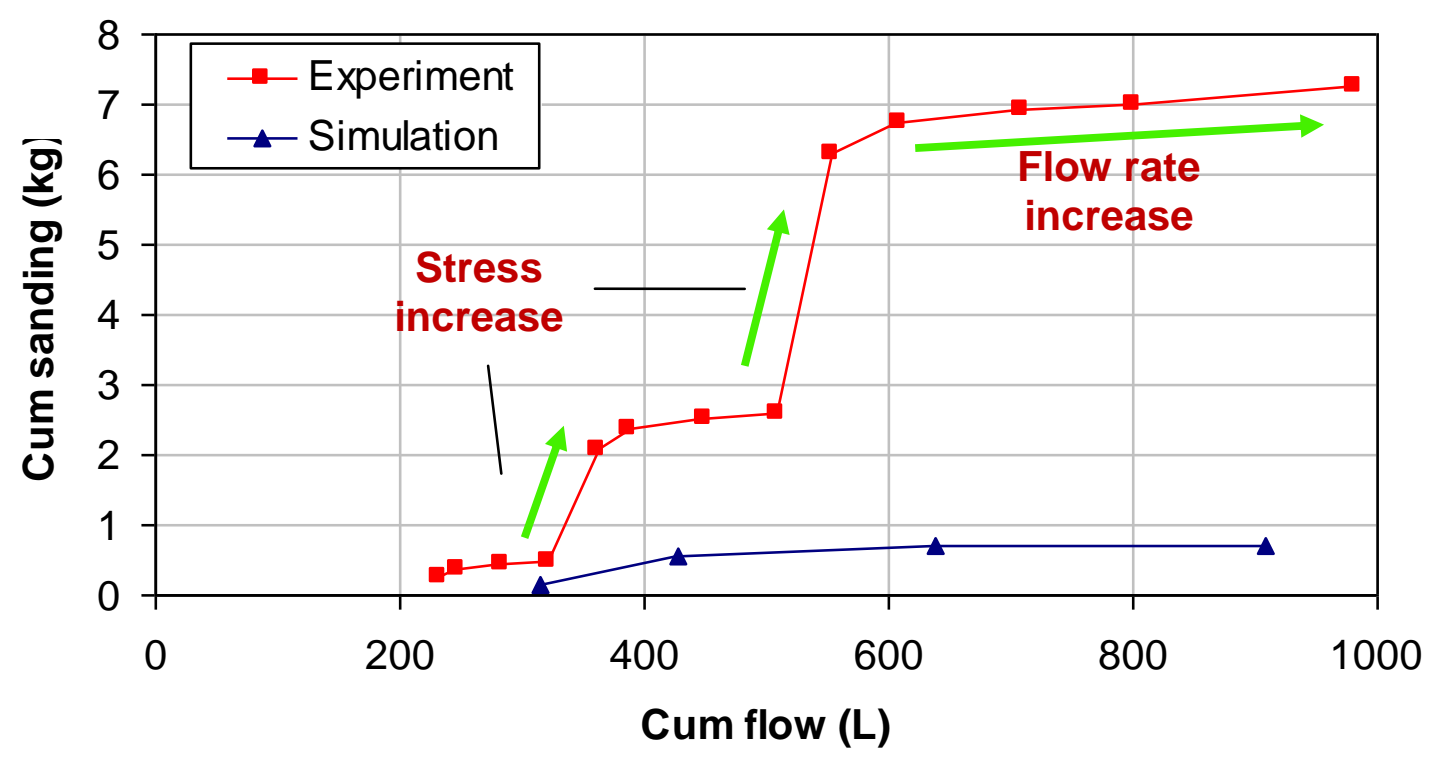

Fig 4.8: Sand production profile with cumulative flow and flow rate (Test \#2)

Test \#3 was very similar to Test \#2, but it was done under smaller confining stresses and lower flow rates. From a plot of the sand produced vs. stress in Fig 4.9, the 
cumulative sand production is higher for the simulation as the stress increases. However, the sand production amount increase at the same stress state due to higher flow rate was smaller than what was observed in the experiment.

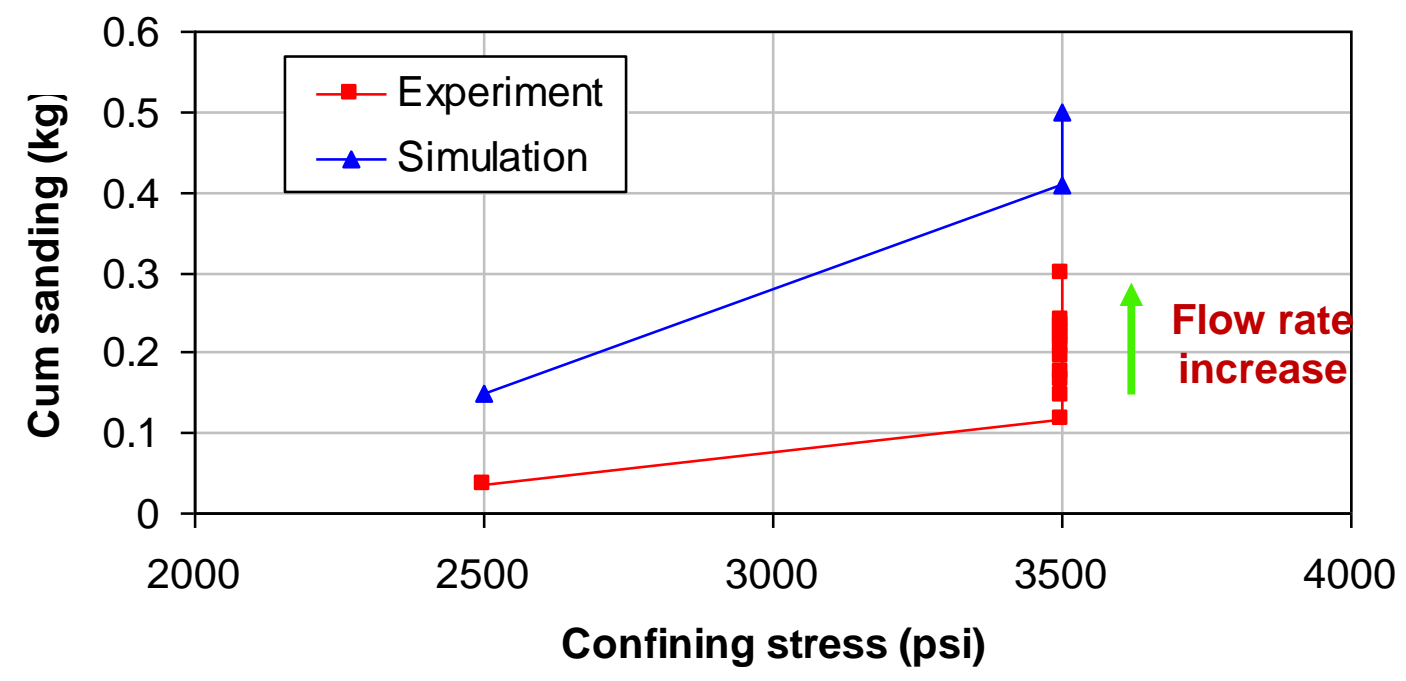

Fig 4.9: Sand production profile with confining stress (Test \#3)

\section{FieLd APPLiCATIONS}

\section{Transition from Experiments to Field - Some Considerations}

Lab experiments usually have vertically orientated cavities. It must be noted that the perforation orientation in vertical wells is horizontal and that the stress directions change significantly from the conventional experimental set up. When using cores from the field, coring parallel to the bedding planes must be done to ensure that sanding characteristics are applicable in the field.

\section{Time Coupling}

Time is not explicitly accounted for in the simulation due to the difficulty of realtime simulation with very small time steps (described in Chapter 3). However, when 
studying the effect of depletion on sanding, an estimate of pore pressure from a reservoir simulator can be used in conjunction with the sanding simulation. Some simulators offer the ability to couple basic geomechanics with reservoir pressure while others cannot.

Regardless, in-situ stresses can be deduced from the reservoir pressure evolution and this can be related to sanding behavior over the life of the well.
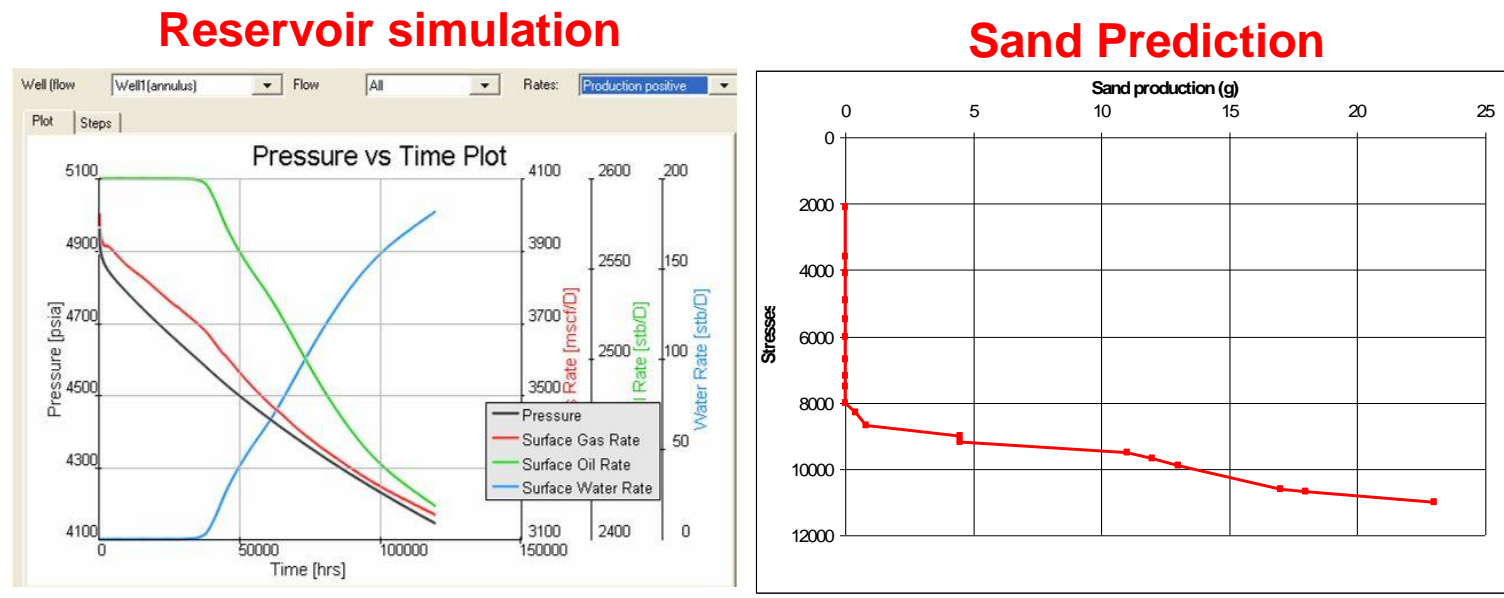

Fig 4.10: Reservoir simulation and sand prediction coupling

a) Reservoir simulation with reservoir pressure change over time

b) Sand prediction with varying stress and pore pressure levels

\section{Specifying Model Parameters}

When applying the model into a field application, the first hurdle is obtaining the relevant parameters. Basic elastic moduli can be calculated using only the sonic log data shown in correlations in Table 4.3. 
Table 4.3: Use of sonic log to predict elastic moduli of materials

\begin{tabular}{|c|c|}
\hline Parameter & Log correlation \\
\hline Poisson's Ratio & $\frac{\frac{1}{2}\left(\Delta t_{s} / \Delta t_{c}\right)^{2}-1}{\left(\Delta t_{s} / \Delta t_{c}\right)^{2}-1}$ \\
\hline Shear Modulus & $\frac{\frac{1}{2}\left(\Delta t_{s} / \Delta t_{c}\right)^{2}-1}{\left(\Delta t_{s} / \Delta t_{c}\right)^{2}-1}$ \\
\hline Bulk Modulus & $1.34 x 10^{10} \rho_{b}\left(\frac{1}{\Delta t_{c}^{2}}-\frac{4}{3 \Delta t_{s}^{2}}\right)$ \\
\hline
\end{tabular}

Table 4.4 lists general parameters required to run a simulation. Methods for obtaining them are different when doing lab tests than when using logs or correlations.

Table 4.4: Methods for obtaining material and petrophysical properties

\begin{tabular}{|c|c|c|}
\hline Parameters & Tests & Log, Correlation \\
\hline UCS or Cohesion & Triaxial tests, scratch test & Sonic log \\
\hline $\begin{array}{l}\text { Hardening / softening, } \\
\text { residual strength }\end{array}$ & Triaxial test & Calibration with MST \\
\hline Friction angle & Triaxial test & \\
\hline Tensile strength & Brazilian tensile test & \\
\hline Dilation angle & Triaxial test & \\
\hline Porosity & Core flooding & Density, neutron, resistivity \\
\hline Permeability & Core flooding & $\begin{array}{c}\text { Porosity vs. permeability } \\
\text { correlation }\end{array}$ \\
\hline Fluid viscosity & Viscometer & \\
\hline Overburden & & Density log \\
\hline $\mathrm{S}_{\mathrm{hmin}}$ & Leakoff test & Caliper log \\
\hline $\mathrm{S}_{\mathrm{hmax}}$ & & Image, caliper log \\
\hline Pore pressure & Formation tester & Density, sonic, resistivity \\
\hline
\end{tabular}




\section{ChaPTER Summary}

Overall, three different sets of distinct experiments were matched with the modelgenerated results. Good agreement between simulation results and experiments was observed with no adjustable parameters (when a complete set of parameters were provided in the experimental study). Some experiments, especially Case 3, did not provide sufficient material properties to conduct an accurate prediction of sanding. Case 1 comparisons showed a very good match for the onset of sanding, sand production trends, and final sand production because of the availability of data for post-failure sand mechanical properties. This example shows the importance of material mechanical testing. The ultimate goal of building a sanding model is to predict sand production under field conditions. Some guidelines are provided for methods that may be used to gather data that is essential for these simulations. 


\section{CHAPTER 5: SENSITIVITY STUDIES}

\section{INTRODUCTION}

The extent of experimental studies is limited by equipment limitations such as pressure ratings and capabilities and the time it takes to conduct such tests. Once a model has been calibrated with experiments, it is instructive to run several cases that show the impact of one parameter while others are held constant. In this chapter, sensitivity studies for stress, drawdown, sand cohesion (consolidation treatments), and permeability are presented.

\section{EFFECT OF STRESS}

External stresses applied to a core sample and in-situ stresses in the field are both critical to cavity failure and subsequent sand production. Because failure is a prerequisite for the erosion process, the effect of stress is important. This sensitivity study does not require a separate simulation because all the cases used for the experimental verification of the model simulate increasing stresses and observe increasing sand production. The purpose of verification using data from Case 2 was to match the numerical model with experimental data that studied the effect of stress on sand production and a successful match was achieved as shown in Fig. 4.4. Fig 5.1 also shows the findings from the experiment in more detail. The experiment shows that the amount of sand produced increases with the external load. This is in good quantitative agreement with the model predictions. 


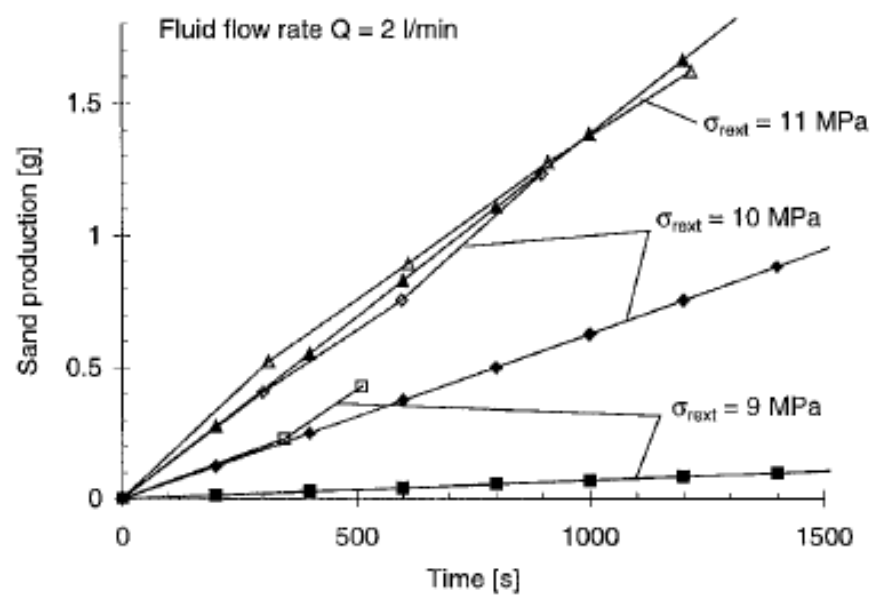

Fig 5.1: Effect of external stress at a constant flow rate (Papamichos, 2001)

\section{EFFECT OF DRAWDOWN}

Understanding the effect of drawdown is critical to managing sand production because drawdown is one of the few parameters that operators can adjust during the production phase. Simulation cases with a higher and a lower drawdown were conducted. First, a base case based on Case 1 simulation stress profiles and material properties with a constant drawdown at $200 \mathrm{kPa}$ was simulated. All the other parameters used in the simulation could be found under Case 1 properties in Table 4.1. Cases with 50, 500, and $900 \mathrm{kPa}$ drawdown were also simulated and compared with the base case. From Fig 5.2, the sand initiation point is similar for all cases. This confirms the speculation from van den Hoek (2000) that initial failure is driven by external stresses rather than drawdown. Even after sand initiation, the difference in sand production with high and low drawdown cases is not clear until the stress value reaches nearly $10 \mathrm{MPa}$. Therefore, it can be concluded that the influence of drawdown becomes more apparent after sand production is initiated. Sand production trends and the final sand production amounts are similar for 
all cases except for the $900 \mathrm{kPa}$ drawdown. This suggests that sufficiently higher drawdown causes a higher pressure drop across the face of the cavity and this enables the hydrodynamic forces to tap into damaged zones that were not produced originally by the base case drawdown.

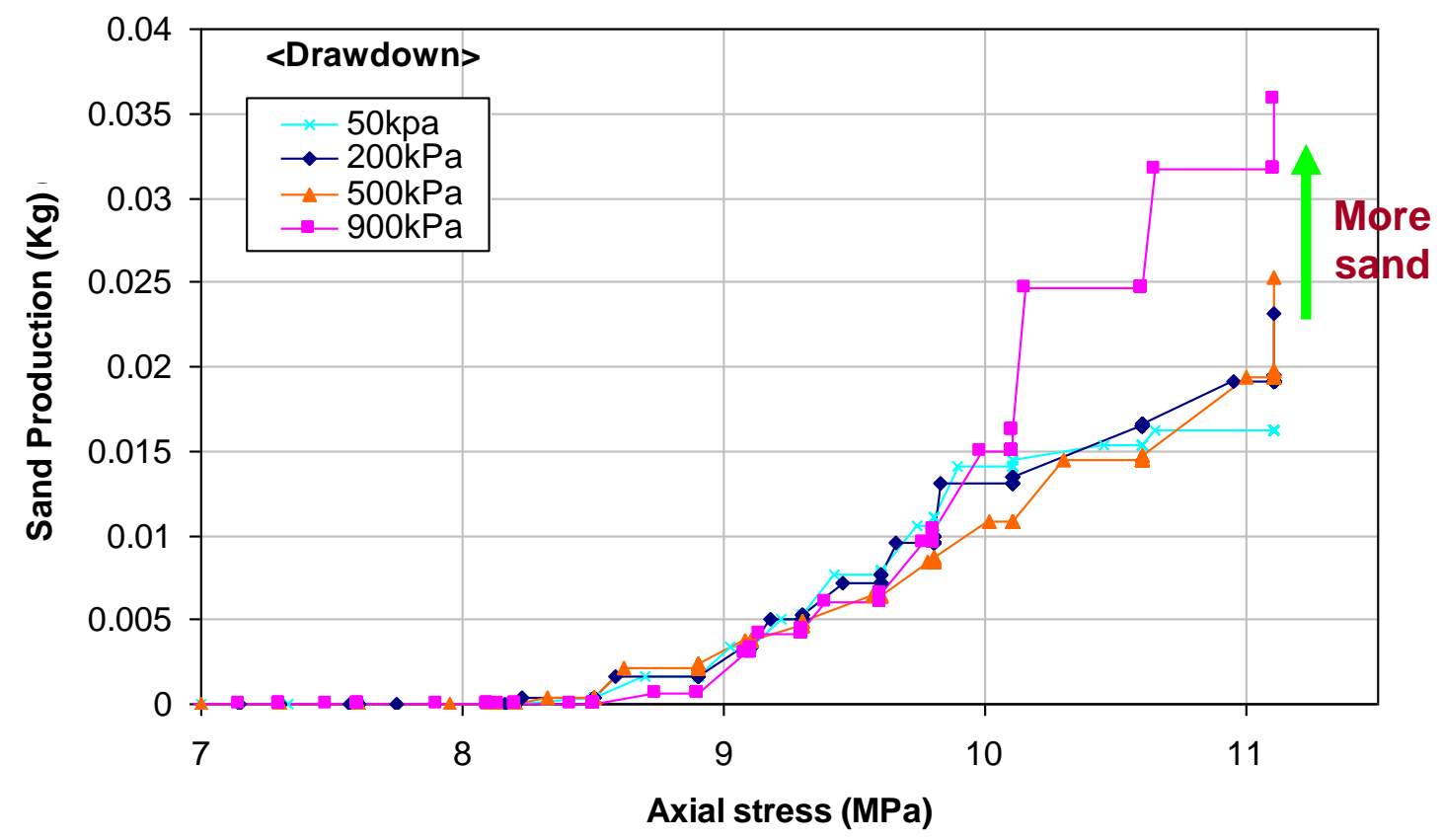

Fig 5.2: Sand production profile with changes in stress and drawdown.

Case 2 (in Chapter 4) also observed a similar effect of drawdown at different external loads. In Fig. 5.3a, the flow rate effect is not clear although sanding had already started when the external stress reached $8 \mathrm{MPa}$. Only at $11 \mathrm{MPa}$ external stress, sand production increased as flow rate is increased. 

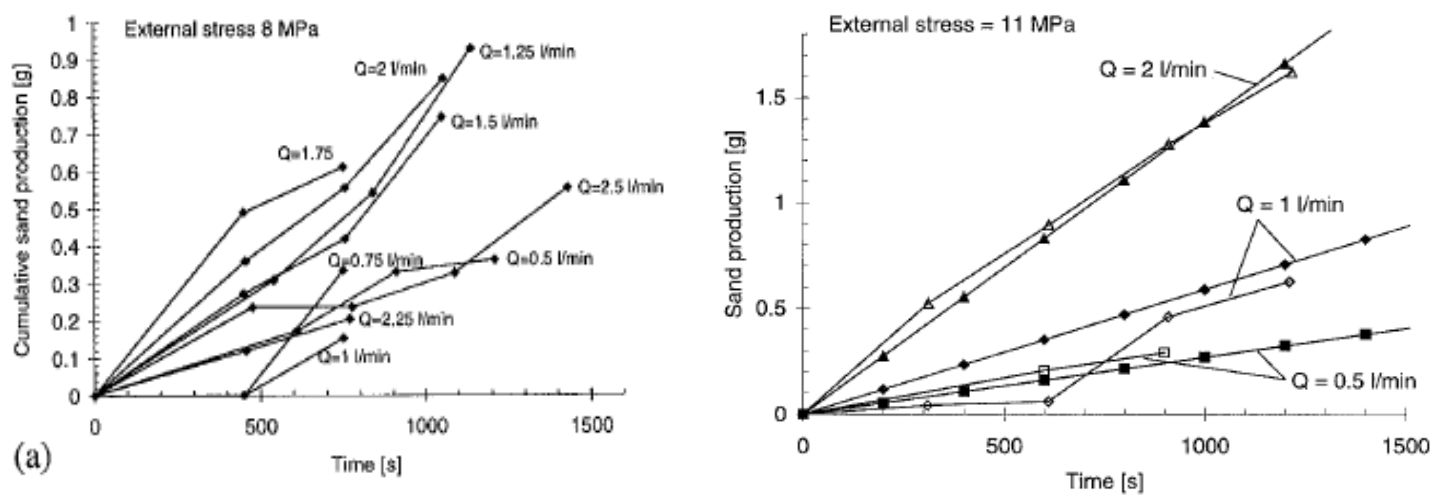

Fig 5.3: Effect of flow rate at constant external stress (Papamichos, 2001)

\section{CONSOlidation / COHESION}

The aforementioned consolidation treatment in Chapter 3 is supposed to help reduce sand production by increasing cohesion. The base case was used to test and quantify the effect of a sand consolidation treatment. Material cohesion was increased by $20 \%$ and its permeability was reduced by $20 \%$ as a result of resin material plugging up some pore space. These assumptions are acceptable as they were often observed in the post-treatment samples. The results in Fig 5.4 suggest that the consolidated formation produces sand at a much higher confining stress. The amount of sand at the end of the test scheme was about 5 grams, which is $80 \%$ less than the base case sand production. Even considering the effect of a $20 \%$ permeability reduction that leads to a reduction of production rate, the sand per barrel in the consolidated formation is far less than what is expected in an untreated formation. Hence, it can be concluded that a consolidation treatment for a sample can be very effective at reducing the mass of sand produced and increasing the effective stress at which sand will fail. Same observations were made from experiments that studied the effectiveness of consolidation in preventing sand production 
(Haggerty, 2009). The financial benefit to operators using the consolidation treatment will vary depending on the tradeoff between the savings in sand disposal and the cost of the treatment. Another case with only the cohesion increased by $20 \%$ was simulated (with no change in the permeability) and the results were almost identical to the results from consolidation treatment case. This shows that the sand production was influenced the most by the change in cohesion not the permeability.

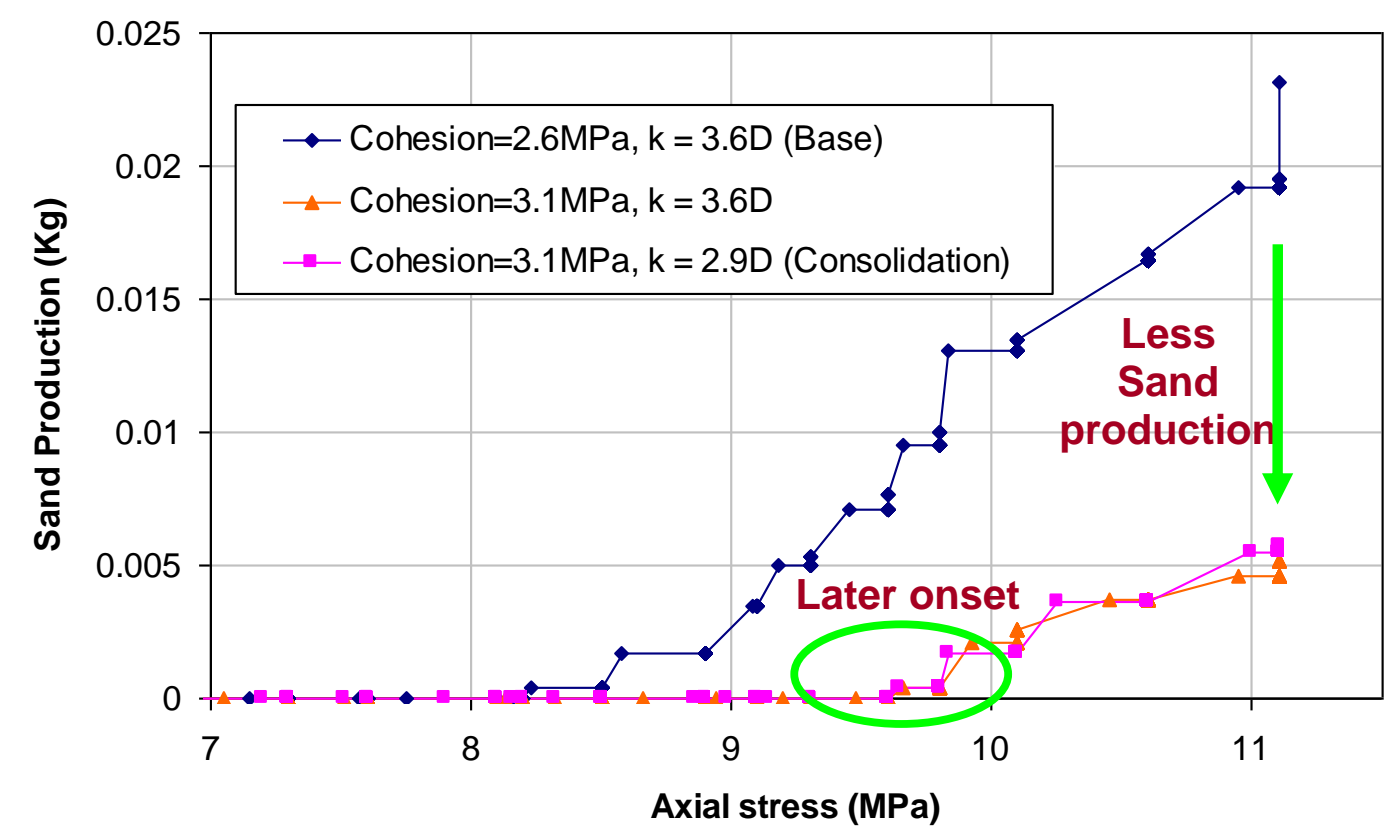

Fig 5.4: Sand production profile for a consolidated sample

\section{Effect of Permeability Changes due to Failure}

Shear dilation can increase the local permeability along the failure plane.

Experimental results suggest that up to a $20 \%$ permeability enhancement can be observed due to shear dilation. To test the sanding behavior under this condition, the simulation 
procedure was modified accordingly. When a zone of failure is detected, the permeability of the failed zone is increased by $100 \%$. The simulation result based on Case 1 shows that there is a slight reduction in sand production (Fig 5.5). This can be understood by noting that in the hydrodynamic force calculation (3.17), a lower pore pressure gradient (caused by a permeability increase in the failed grid blocks) results in a reduction in the hydrodynamic force, making sand erosion less likely. The onset of sanding remains the same as the base case. Therefore, a $100 \%$ increase in permeability does not have a significant impact on sand production.

Formation damage can occur because of perforating processes and fines migration. Although there is no detailed information on the degree of permeability reduction caused by the formation damage, a sensitivity case with a $50 \%$ reduction in the permeability in the failed grid blocks was run. The simulation shows a significant increase in the sand production amount. Intuitively, the permeability reduction near the wellbore (only in the failed grid blocks) causes a higher pore pressure gradient according to Darcy's law. The hydrodynamic force increases with a higher pore pressure gradient and this leads to more sand production because more zones met the erosion criteria. 


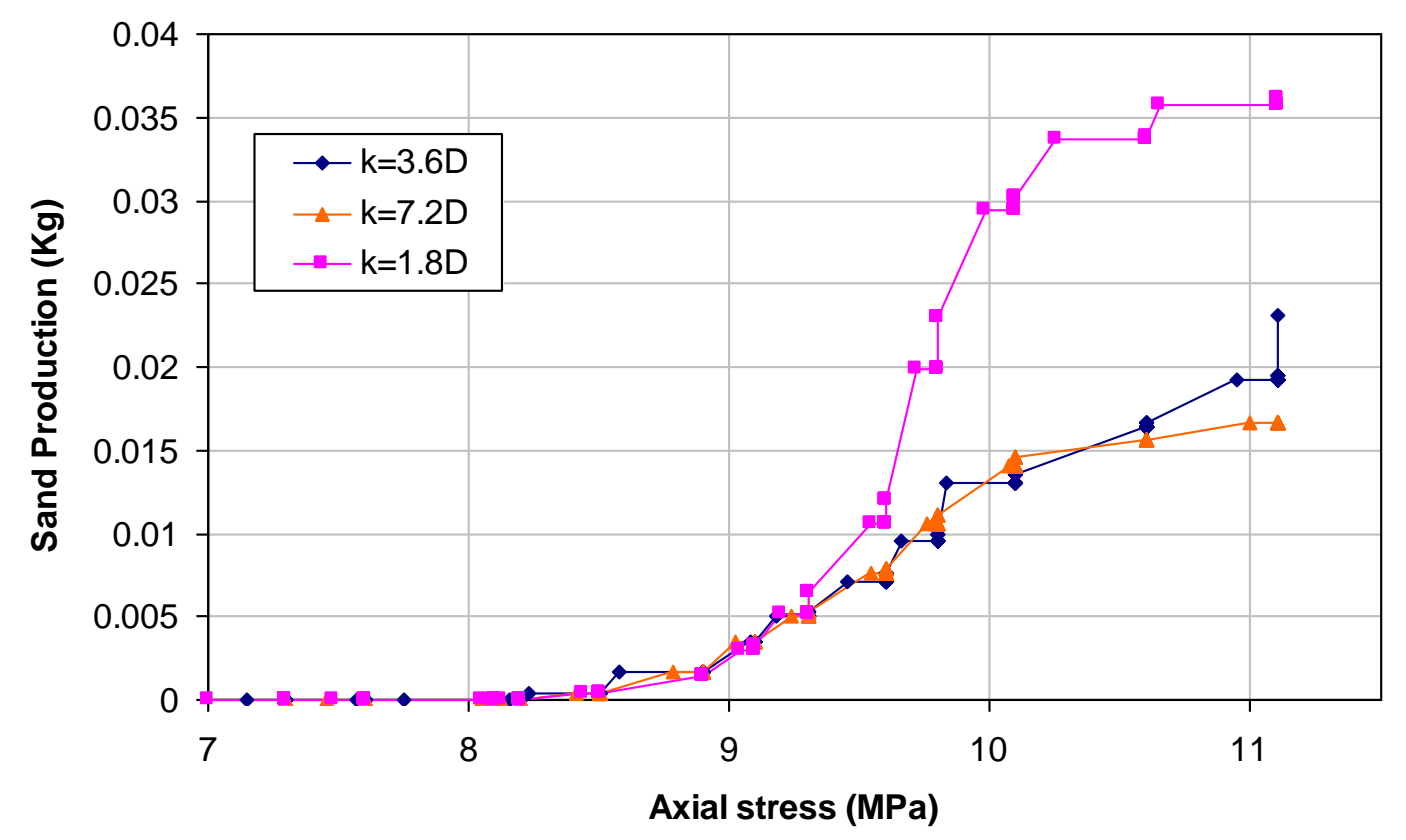

Fig 5.5: Sand production profiles for permeability changes imposed on failed region

\section{Chapter Summary}

Sensitivity studies with the model show the effect of in -situ stresses, drawdown, cohesion, and permeability. With higher stress, a larger region of failure develops and the sand production increases. The effect of different petrophysical parameters and drawdown becomes significant when the applied stress is large enough to induce failure. This implies that the influence of drawdown and permeability are important only when the region of failure enlarges due to a large enough stress. Changes in material properties, such as cohesion can be used to alter the onset of sanding. This allows us to prevent sand production and minimize its effects. 


\section{CHAPTER 6: SAND PRODUCTION IN MULTIPHASE FLOW}

\section{INTRODUCTION}

Water breakthrough in producing wells can occur due to infiltration from an aquifer or from an injection well. Regardless of the cause, water always brings about the onset of more sand production. From the completions engineer's point of view, managing this water production and the sand production is a very important design parameter.

\section{SAND STREngth vs Water SATURATion}

Water can significantly weaken the strength of rocks by weakening the intergranular cementation depending on the chemical composition and the reactivity of the cementing material and the loss of capillary cohesion between the sand grains. This translates into a reduction in the mechanical cohesion between rocks. Elastic moduli are affected and the behavior of the rock changes. Papamichos (2010) discusses the degradation of mechanical properties in water saturated samples. UCS and Young's modulus of water saturated samples measured about $70 \sim 80 \%$ of those in unsaturated samples. This mechanical strength alteration holds true for both fully-saturated rocks and rocks at the irreducible water saturation. Due to the UCS and Young's modulus change, the stress at failure also changes for water saturated samples. Most sandstones contain some clay and some swelling can occur when clays come into contact with water. Other than the physical changes that take place with water invasion, there can be geochemical interactions. Fines migration induced by the onset of water production can cause plugging of the pore space and cause high pore pressure gradients, which are not favorable to sand production. 


\section{Effect of Two-phase Flow on SAnd Production}

One of the most important components of inter-granular cohesion is capillary pressure. In competent formations or even in weaker rocks before failure, cohesion supplied by mechanical cementation provides a major resistance to shear failure. In competent rocks, capillary pressure is generally negligible because it is smaller than the mechanical cohesion (cementaton) by orders of magnitude. However, once the cementing material fails and the mechanical cohesion is reduced to a residual value, or in rocks that are completely unconsolidated, capillary forces become a dominant cohesion mechanism. Capillary forces can only be included on a grain scale (Prodanovic, 2009). However, the scale of such model is presently prohibitively small. Formation of a strong post-failure structure in two-phase flow at irresidual water saturation proves that the contribution from capillary forces is significant because there is less post-failure sand production observed in single-phase flow. This is confirmed from experiments as shown in Fig 6.1. The X-axis of the plot represents the normalized excess stress where SPS is the sand production stress and $\sigma_{\mathrm{c}}$ is the confininng stress. Normalizing the stress allows the authors to focus on the effect of saturation and stress on sand production after failure. $\mathrm{S}_{\mathrm{o}}$ and $S_{w}$ both represent cases with single-phase flow and the subscript denotes the flowing phase (oil or brine). $\mathrm{S}_{\mathrm{wi}}$ cases are initially saturated at irreducible water saturation and the oil flows through the sample except for the one case, during which the oil flow is switched to a brine flow. Fig 6.1 shows that the single-phase flow cases reach the maximum sand production with a slight increase of the confining stress after the sand production starts. More confining stress was required to reach the maximum production 
in cases with irreducible water saturation. When the oil flow was switched to brine, the sanding behavior was close to that of a single-phase system, which shows the catastrophic effect of water breakthrough.

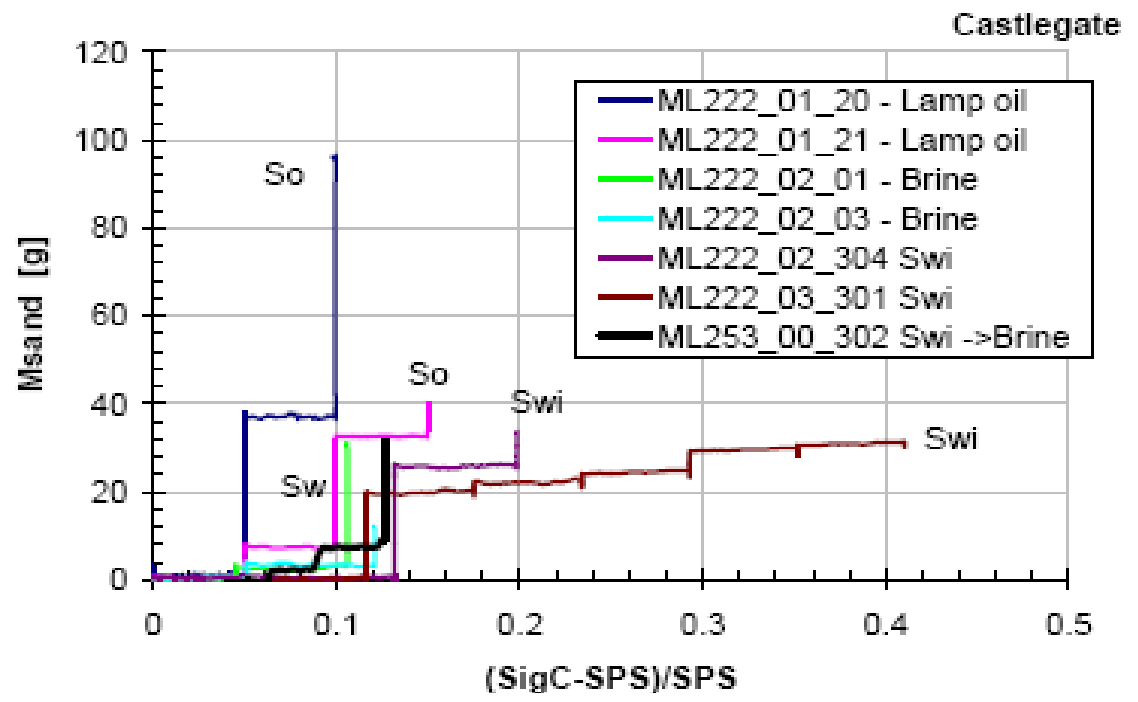

Fig 6.1: Effect of single-phase and two-phase flow on sand production (Papamichos, 2010)

Brine-only flow and oil flow at irreducible water saturation was simulated in the numerical model. Both cases had the same material properties, applied stress, and drawdown profiles. To account for capillary forces in two-phase flow, $5 \mathrm{kPa}$ of cohesion was added after the onset of failure. At the end of each simulation, the amount of sand production was recorded. Fig 6.2 has a remarkable resemblance to the sanding profile in Fig 6.1, showing that introducing a slight increase in cohesion in the post-failure stage shows less sand production under the same confining stress. 


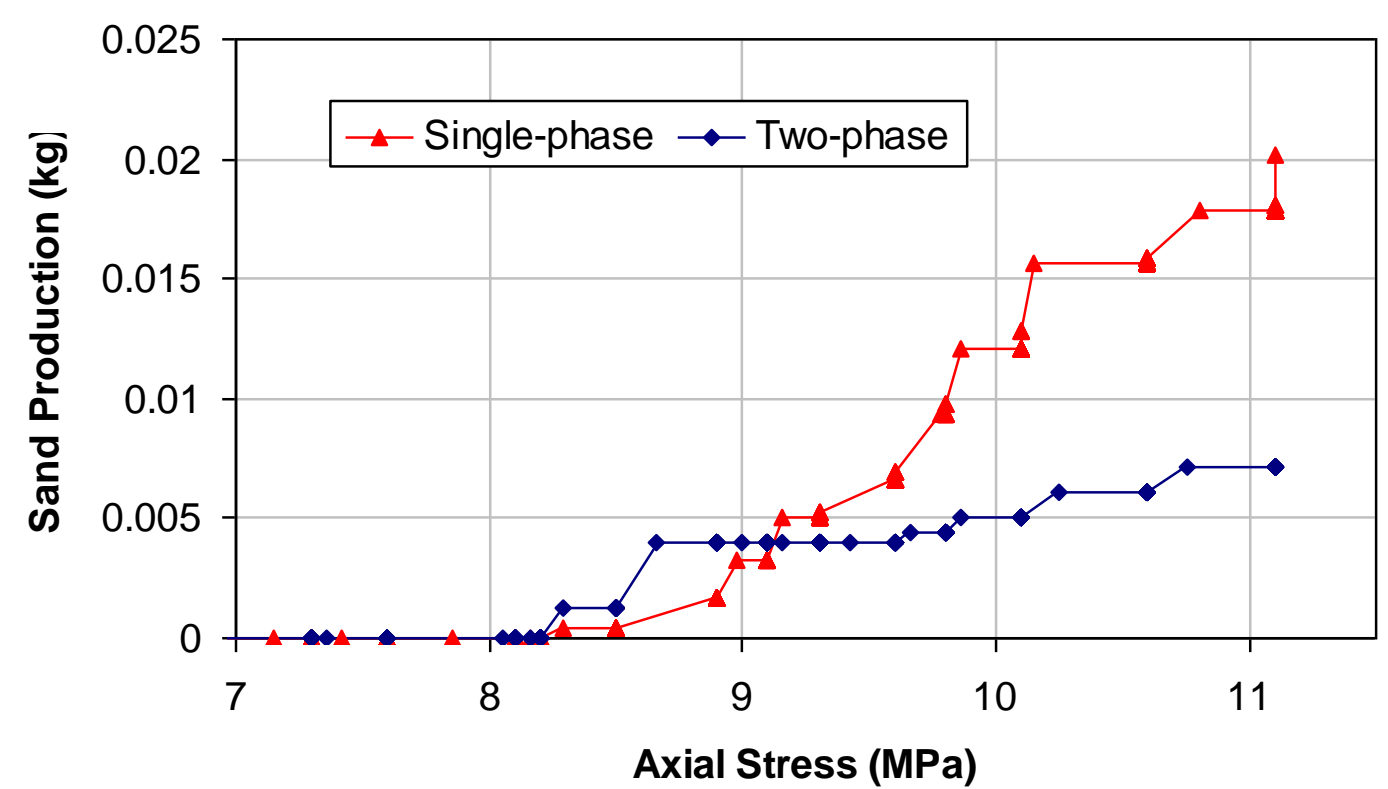

Fig 6.2: Effect of single-phase and two-phase flow on sand production

\section{Simulation of Sand Production in Two-Phase Flow}

When water sweeps the reservoir and breaks through into the prodcing well, the water saturation of the plastified region increases. The capillary cohesion forces are very sensitive to the change in water saturation. As shown in Fig 6.3, increasing water saturation adversely affects cohesion at saturations exceeding irreducible water saturation. This can lead to complete degradation of the binding forces holding the sand grains together and sand failure occurs. Note that sand production due to water is limited to disaggregated particles which cover most of the cavity surface. The volume of sand production due to water is equal to the volume of disaggregated grains in the damaged zone. 


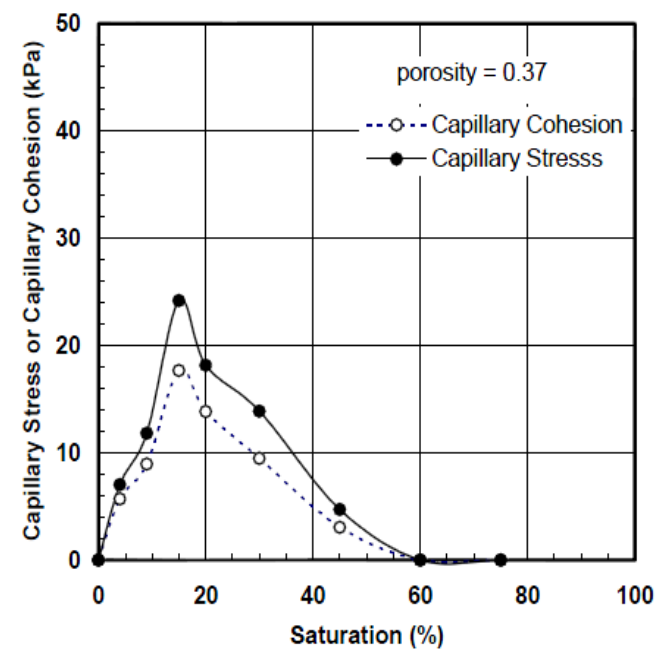

Figure 13. Capillary stress or capillary cohesion as a function of water saturation, compacted loose sand.

Fig 6.3: Effect of water saturation on capillary cohesion $(\mathrm{Wu}, 2006)$

FLAC3D cannot simulate multiphase flow. The only way to model the effect of water is to adjust cohesion. To simulate the influence of water for the experimental Case 1, the base case simulation was used. Under the same mechanical stress and drawdown, cohesion was lowered by $10 \%$ in each step to simulate the decrease in cohesion due to an increase in water saturation. This reduction in cohesion was conducted in ten steps until cohesion reached zero to simulate a complete loss of cohesion at high water saturation. Fig 6.4 shows a profile for the cohesion drop (blue) that resembles the curve from Fig 6.3. At each cohesion value, the simulator conducted the coupled calculations and detected any further sand production. Although there is more to be considered with regards to applying cohesion alteration in the model formulation, this simulation demonstrates that lowering cohesion values singlehandedly caused a $100 \%$ increase in sand production from the state of equilibrium prior to water breakthrough. This pattern 
coincides with an abrupt and massive sand production beyond irreducible brine saturation as given shown in Fig 6.5.

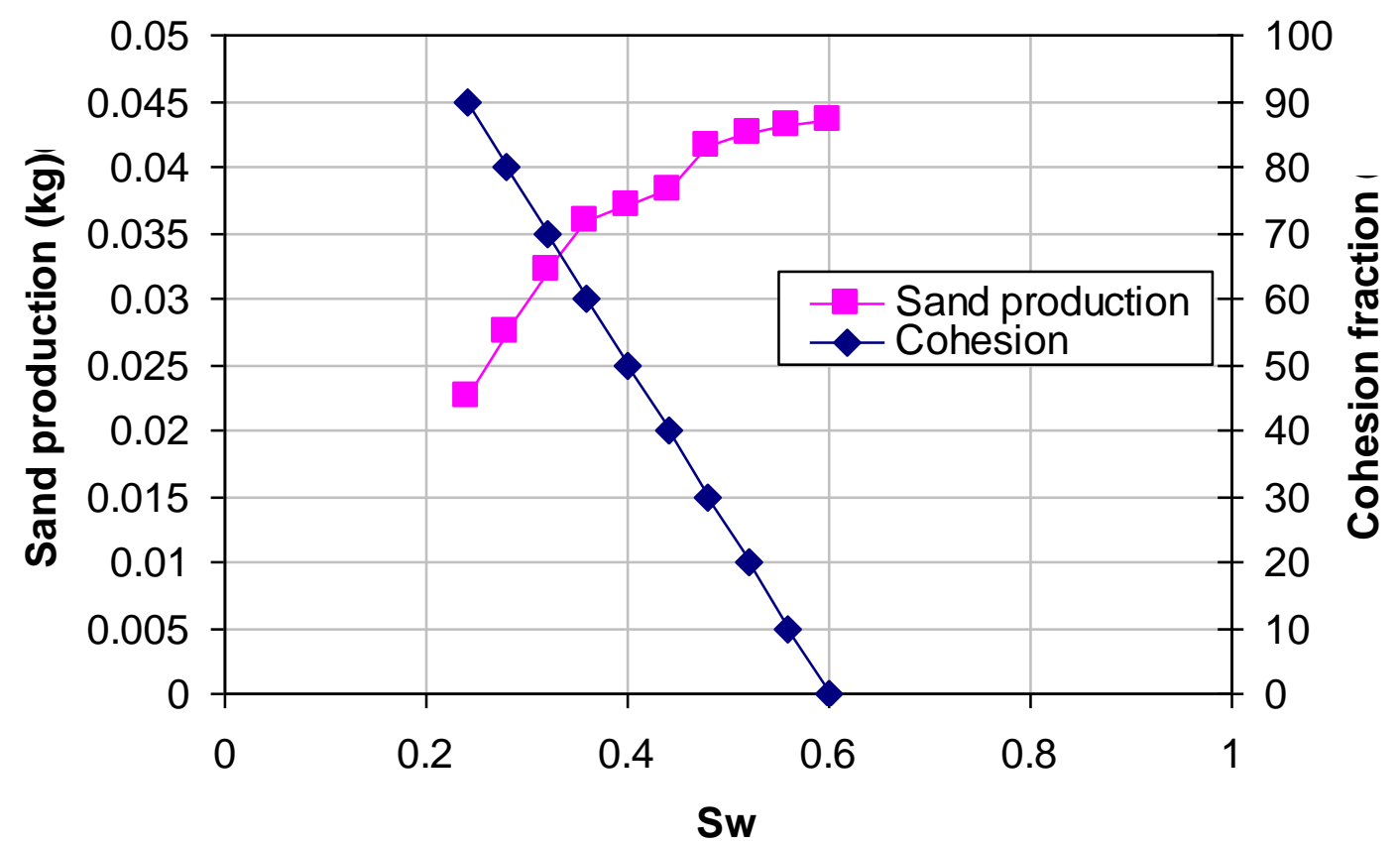

Fig 6.4: Simulation of additional sand production caused by an increase in water saturation.

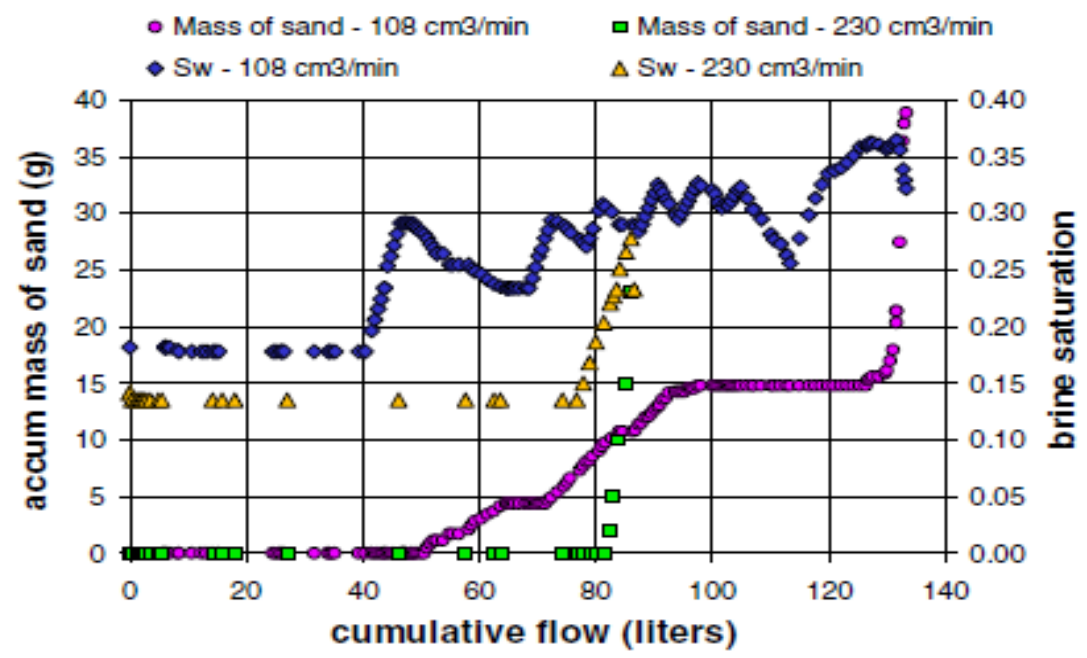

Fig 6.5: Sanding with increasing water saturation (Bianco, 2001) 


\section{CHAPTER 7: CONCLUSIONS AND RECOMMENDATIONS}

The onset of sand production and the mass of sand produced are extremely important factors in choosing an optimal completion strategy. Failure to prevent sand production can result in safety risks, facilities challenges and a significant impairment to well production. A predictive model was developed to provide an assessment of the sanding potential of a well based on reservoir properties, completion geometry as well as operational parameters.

The sand production model incorporates two sequential phenomena. The first one is the failure of the near-wellbore region (wellbore or perforation), which is a necessary condition for any sand production. The subsequent step for sand production is "erosion." This process refers to the removal of the sand from the failed region. In the model, a force balance is conducted between the frictional forces mechanically holding the sand in the formation and the hydrodynamic force (exerted by the flow) that induces detachment of the disaggregated sand. Grid blocks for which the frictional force is overcome by the hydrodynamic force are removed from the simulation and are assumed to be produced into the well.

Several experimental cases, taken from the literature, were simulated. Experimental values of the given material properties were used and no deliberate adjustment of parameters was made to improve matches with experiments. The modelgenerated results were compared with the experiments. The onset of sand production and the amount of sand produced agreed well with the experimental values for most cases. When detailed post-failure material properties were given, the model generated results matched the experiment very well in terms of the onset of sand initiation, and the cumulative sand production. This shows the importance of experimentally measuring 
such parameters. It was found from sensitivity studies that material and reservoir property changes can have different implications in sand production behavior. As expected, increasing mechanical stresses resulted in a more sand production. This is due to the enlargement of the failed sand region at a higher stress level, making more material available for erosion. An increase in flow rate or pore pressure gradient increases the hydrodynamic force allowing it to overcome the force holding the disaggregated sand in place. Sand consolidation treatments that strengthen the formation reduce the sand production, while water weakens the sand and can cause massive sand production. Both cases are modeled through a change in the material cohesion. Simulation results indicate that an increase in cohesion enhances the ability of the formation to withstand more mechanical stress before the onset of failure. At reduced cohesion levels, the formation is more prone to failure and the sand production increases.

This thesis presents a sand prediction model that forms a basis for understanding sand production and for making predictions for the onset of sand production and the amount of sand expected to be produced after failure. In the future, more effort is needed to understand the impact of sand consolidation resins and two-phase flow behavior, especially in terms of capillary forces. Additional parametric studies on stress anisotropy, perforation orientation, and material property dependence can provide a better insight to sand failure in the field. The ultimate use of this model will be for field predictions, hence the model implementation, which has been focused on quantitative comparisons with lab experiments, must be updated to accept input from logs and other correlations and the model results need to be confirmed with field observations. 


\section{REFERENCES}

1. Bratli, R. K. and Risnes, R. Stability and Failure of Sand Arches. 1981. Society of Petroleum Engineers Journal 0197-7520.

2. Risnes, R., Bratli, R. K., and Horsrud, P., 1982. Sand Stresses Around a Wellbore. SPE 9650.

3. Addis, M. A., Gunningham, M. C., et al. 2008. Sand Quantification: The Impact on Sandface Completion Selection and Design, Facilities Design and Risk Evaluation. SPE 116713 presented at the 2008 SPE Annual Technical Conference and Exhibition, Denver, CO, USA, Sept 2008.

4. Hall, C. D. and Harrisberger, W. H. 1970. Stability of Sand Arches: A Key to Sand Control. Journal of Petroleum Technology.

5. Perkins, T. K. and Weingarten, J. S. 1988. Stability and Failure of Spherical Cavities in Unconsolidated Sand and Weakly Consolidated Rock. SPE 18244 presented at Annual Technical Conference and Exhibition, Houston, TX, Oct 2005.

6. Morita, N., Whitfill, D.L., Fedde, O.P., and Levik, T.H., 1989. Parametric Study of Sand-Production Prediction : Analytical Approach. SPE 16990.

7. Veeken, C. A. M., Davids, D. R., Kenter, C. J., et al. 1991. Sand Production Prediction Review: Developing an integrated Approach. SPE 22792 presented at the 1991 SPE Annual Technical Conference and Exhibition, Dallas, TX, October, 1991. 
8. Tronvoll, J., Dusseault, M. B., Sanfilippo, F., et al., 2001. The Tools of Sand Management. SPE 71673 presented at the 2001 SPE Annual Technical Conference and Exhibition, New Orleans, LA, USA, Sept 2001.

9. Van den Hoek, P. J., Hertogh, G. M. M., Kooijman, A. P., et al., 2000. A New Concept of Sand Production Prediction: Theory and Laboratory Experiments. SPE 65756

10. Willson, S. M., Moschovidis, Z. A., et al., 2002. New Model for Predicting the Rate of Sand Production. SPE 78168 presented at SPE/ISRM Rock Mechanics Conference, Irving, TX, October 2002.

11. Abass H. H., Nasr-El-Din, and BaTaweel, M. H., 2002. Sand Control : Sand Characterization, Failure Mechanisms, and Completion Methods. SPE 77686 presented at the SPE Annual Technical Conference and Exhibition, San Antonio, September, 2002.

12. Kooijman, A. P., van den Hoek, P. J., de Bree, P., et al., 1996. Horizontal Wellbore Stability and Sand Production in Weakly Consolidated Sandstones. SPE 36419 presented at the 1996 SPE Annual Technical Conference and Exhibition, Denver, CO, USA, October 1996.

13. Wang, J., Wan, R. G., Settari, A., et al., 2004. Sand Production and Instability Analysis in a Wellbore using a Fully Coupled Reservoir-Geomechanics Model.

14. Pacheco, E., Soliman, M.Y., et al. 2009. Sanding Prediction in a Gas Well Offshore Mexico Using a Numerical Simulator. SPE 122962 presented at SPE 
Latin American and Caribbean Petroleum Engineering Conference, Cartagena, Colombia, May 2009.

15. Chin, L. Y. and Ramos, G. G., 2002. Predicting Volumetric Sand Production in Weak Reservoirs. SPE/ISRM 78169 presented at the SPE/ISRM Rock Mechanics Conference Irving, TX, October 2002.

16. Papamichos, E., Vardoulakis, I., Tronvoll, J., et al., 2001. Volumetric Sand Production Model and Experiment. International Journal for Numerical and Analytical Methods in Geomechanics, 25:789-808.

17. Fjær, E., Cerasi, P., Li, L., and Papamichos, P., 2004. Modeling the Rate of Sand Production. ARMA 04-588 presented at the $6^{\text {th }}$ North America Rock Mechanics Symposium, Houston, TX, June 2004.

18. Detournay, C., Tan, C., and Wu, B., 2006. Modeling the mechanism and rate of sand production using FLAC. Paper 08-10 at $4^{\text {th }}$ International FLAC Symposium on Numerical Modeling in Geomechanics.

19. Nouri, A., Vaziri, H., and Belhaj, H., 2004. Sand Production Prediction: A New Set of Criteria for Modeling Based on Large-Scale Transdient Experiments and Numerical Investigation. SPE 90273 presented at the SPE Annual Technical Conference and Exhibition, Houston, TX, USA, 26-29 September 2004.

20. Papamichos, E., Stenebraten, J., Cerasi, P., et al., 2008. Rock Type and Hole Failure Pattern Effects on Sand Production. ARMA 08-217 presented at $42^{\text {nd }}$ US Rock Mechanics Symposium, San Francisco, CA, June 2008. 
21. Han, G., Shepstone, K., Harmawan, I., et al. 2009. A Comprehensive Study of Sanding Rate From a Gas Field: From Reservoir, Completion, Production, to Surface Facilities. SPE 123478 presented at SPE Annual Technical Conference and Exhibition, New Orleans, LA, October 2009.

22. Bruno, M. S., Bovberg, C. A., and Meyer R. F., 1996. Some Influences of Saturation and Fluid Flow on Sand Production; Laboratory and Discrete Element model Investigations. SPE 36534 presented at the 1996 SPE Annual Technical Conference and Exhibition, Denver, CO, October 1996.

23. Bianco, L. C. B. and Halleck, P. M., 2001. Mechanisms of Arch Instability and Sand Production in Two-Phase Saturated Poorly Consolidated Sandstones. SPE 68932 presented at the European Formation Damage Conference, Hague, The Netherlands, May 2001.

24. Wu, B., Tan, C. P., and Lu, N., 2006. Effect of Water Cut on Sand Production An Experimental Study. SPE 92715 presented at the 2005 Asia Pacific Oil \& Gas Conference and Exhibition, Jakarta, Indonesia, October 2005.

25. Nouri, A., Vaziri, H., Kuru, E., Belhaj, H., Islam, M.R., 2007. Physical and Analytical Studies of Sand Production from a Supported Wellbore in Unconsolidated Sand Media with Single- and Two-Phase Flow.

26. Papamichos, E., Cerasi, P., and Brignoli, M., 2010. Sand Production Rate under Multiphase Flow and Water Breakthrough. June 2010. 
27. Vaziri, H., Nouri, A., Hovern, K., et al., 2007. Computation of Sand Production in Water Injectors, SPE 107695 presented at the European Formation Damage Conference, Scheveningen, The Netherlands, May 2007.

28. Palmer, I., Vaziri, H., Willson, S., et al., 2003, Predicting and Managing Sand Production : A New Strategy. SPE 84499 presented at the 2003 SPE Annual Technical Conference and Exhibition, Denver, CO, USA, October 2003.

29. Fjær, E., Holt, R.M., Horsrud, P., Raaen, A.M., and Risnes, R., 2008. Petroleum Related Rock Mechanics. $2^{\text {nd }}$ Edition. ELSEVIER.

30. Yi, X., Valko, P., and Russel, J.E., 2004. Predicting Critical Dawdown for the Onset of Sand Production. SPE 86555 presented at the SPE International Symposium and Exhibition on Formation Damage Control, Lafayette, LA, February 2004.

31. Cundall, PA and Strack, ODL., 1979. Discrete Numerical-Model for Granular Assemblies. Geotechnique, vol 29, issue 1, pages 47-65.

32. Haggerty, D.J., Manning, J.D., Nguyen, P.D., Rickman, R.D., Dusterhoft, R.G., 2009. Sand Consolidation Testing in an API RP 19B Section IV Perforation Flow Laboratory, SPE 120901 presented at the 2009 SPE European Formation Damage Conference, Scheveningen, The Netherlands, May 2009.

33. Papamichos, E., et al., 2010. Sand Production Rate under Multiphase Flow and Water Breakthrough, ARMA $10-340$ presented at the $44^{\text {th }}$ US Rock Mechanics Symposium, Salt Lake City, UT, June, 2010.

34. User Manual - FLAC3D 3.1, Itasca Consulting Group, www.itascacg.org, 2006. 


\section{VITA}

Sung Hyun Kim was born in Seoul, South Korea in 1983. He received a B.S. degree in aerospace engineering from University of Illinois at Urbana Champaign in 2005. He pursued a higher education at Texas A\&M University in aerospace engineering and received a M.S. degree in 2008. He was a graduate research assistant at the department of petroleum and geosystems engineering at the University of Texas at Austin from 2008 to 2010 .

This thesis was typed by the author. 